\title{
ATHEISM AND AGATHEISM IN THE GLOBAL ETHICAL DISCOURSE: REPLY TO MILLICAN AND THORNHILL-MILLER
}

\author{
JANUSZ SALAMON \\ Charles University in Prague
}

\begin{abstract}
Peter Millican and Branden Thornhill-Miller have recently argued that contradictions between different religious belief systems, in conjunction with the host of defeaters based on empirical research concerning alleged sources of evidence for 'perceived supernatural agency', render all 'first-order', that is actual, religious traditions positively irrational, and a source of discord on a global scale. However, since the authors recognise that the 'secularisation thesis' appears to be incorrect, and that empirical research provides evidence that religious belief also has beneficial individual and social effects, they put forward a hypothesis of a 'second-order religious belief', with Universalist overtones and thus free of intergroup conflict, and free of irrationality, since supported (solely) by the Fine-Tuning Argument. While granting most of their arguments based on empirical research and embracing the new paradigm of the atheism/religion debate implicit in their paper, I contend that Millican's and Thornhill-Miller's proposal is unlikely to appeal to religious believers, because it misconstrues the nature and grounds of religious belief. I suggest that their hypothesis may be refined by taking into account a view of axiologically grounded religious belief that I refer to as 'agatheism', since it identifies God or the Ultimate Reality with the ultimate good (to agathon). I submit that agatheistic religious belief which is explicitly or implicitly presupposed in the first-order religious traditions as their doxastic core can be shown to be rational, and allows us to frame the relations between fundamental beliefs of adherents of various religions and worldviews in a non-conflictual way, conducive of their constructive participation in the global ethical discourse.
\end{abstract}

For science can only ascertain what is, but not what should be, and outside of its domain value judgments of all kinds remain necessary. Religion, on the other hand, deals only with evaluations of human thought and action [...] If one conceives of religion and science according to these definitions then a conflict between them appears impossible. (Albert Einstein) ${ }^{1}$

\footnotetext{
${ }^{1}$ Albert Einstein, "Science and Religion", in Out of My Later Years (New York: Philosophical Library/Open Road, 2011 (first published in 1950)), pp. 37-38.
} 
Darwin didn't preach Darwinism. His theory does not dictate any specific form of behaviour. Nature is not interested in individuals. It has no moral content at all. But to be a human being is to have certain moral ideals, in which case we must resist certain natural processes in a way that lions and tigers can't. And therefore what can be called ideology can be made independent of scientific findings. Goals are not provided by science. (Isaiah Berlin) ${ }^{2}$

\section{SEARCHING FOR A NEW PARADIGM OF THE ATHEISM/RELIGION DEBATE}

In this time, when the tide of us-versus-them mentality is once again on the rise across the globe, it is refreshing to come across a careful study of the epistemology of religious belief marked by intellectual empathy and the spirit of dialogue. ${ }^{3}$ Co-authored by Peter Millican, an analytic philosopher and a leading Hume scholar, representing "a sceptical and naturalistic attitude to religion", and by his Oxford colleague, Branden ThornhillMiller, a psychologist "sympathetic to religious claims and informed by contemporary empirical research", the work is itself "a product of a dialogue between two contrasting points of view", conducted with the aim to "encourage more progress in interreligious dialogue and in the naturalism/ supernaturalism debate" (p. 2). While not being in full agreement as to whether and how "to accommodate our natural religious tendencies within our intellectual lives", both authors agree that "there is plenty of scope for reasonable debate here, and the verdict is less clear cut than is commonly supposed by enthusiasts on either side" (p. 5). As such the discussion provides a new model of how philosophy of religion may be practiced, and is an anti-thesis of the usual highly-charged polemics between 'new atheists' and 'full-time apologists', shooting at each other in the preaching-to-thechoir manner and with predictable results.

True to the spirit of their own call to dialogue and constructive debate, while outlining "some of the possibilities and rational limits of supernatural religious belief" and concluding that "the contradictions between different religious belief systems, in conjunction with new understandings of the cognitive forces that shape their common features, persuasively challenge

${ }^{2}$ Isaiah Berlin in a 1974 BBC interview with John Merson; cf. The Isaiah Berlin Virtual Library: <http://berlin.wolf.ox.ac.uk/lists/interviews/> [accessed 1/10/2015].

${ }^{3}$ Branden Thornhill-Miller and Peter Millican, "The Common-Core/Diversity Dilemma: Revisions of Humean Thought, New Empirical Research, and the Limits of Rational Religious Belief", European Journal for Philosophy of Religion, Vol. 7, no. 1 (2015), 1-49. Subsequent references to this work are included parenthetically in text. 
the rationality of most kinds of supernatural belief" (p. 1), ${ }^{4}$ the authors bother to put themselves in the shoes of the traditional religious believers in order to articulate what might be the epistemically best option available to those who find themselves unable "to 'bite the bullet' of cool, parsimonious reason and learn to live with a godless world" (p. 46). The outcome of this exercise in intellectual empathy is a hypothetical religious stance which Thornhill-Miller and Millican call 'second-order religion' or 'second-order supernaturalism', leaving the term 'first-order religion' to designate the actual historical religions. The second-order religion is supposed to be a kind of 'thin' theism or deism (perhaps too thin, as I will argue, to deserve to be called 'religion') supported solely by the Fine-Tuning Argument for the existence of God which builds on the recent "apparent discovery of certain 'anthropic coincidences' in the laws of physics" (p. 4), without which the existence of life in general, and of creatures like humans in particular, would be impossible. No other theistic argument deserves, in their opinion, such credit, ${ }^{5}$ and in the face of numerous defeaters grounded in "empirical research concerning intercessory prayer, religious experience, near-death experience, and various cognitive biases, such as agency detection, theory of mind, egocentric and confirmation bias", in addition to the aforementioned "mutual contradictions of first-order supernaturalism" (p. 1), no first-order religion can be supported by a rational argument, and therefore - as is implied throughout the paper - commitment to the truth-claims of some particular religious tradition is positively irrational. ${ }^{6}$

At this stage a reader might ask herself, how does this line of argument differ from other all-out philosophical criticisms of religious belief? Arguably there are at least two aspects to Thornhill-Miller's and Millican's approach to the subject matter which deserve attention as containing the germs of two interesting projects that might contribute to rejuvenation of the philosophical atheism/religion debate, potentially turning it into something more meaningful and fruitful than it usually is. Firstly, Thornhill-Miller and Millican explore not just the question of "the rational limits" of religious belief, but also of the "possibilities" of rational religious

\footnotetext{
${ }^{4}$ In all cases, including in quotations, when emphasis is added by the use of italics, the italics are mine, unless specified otherwise.

${ }^{5}$ Cf. footnote 143 on p. 47.

${ }^{6}$ The position adopted by the authors of the paper regarding the rationality of commitment to particular religious creeds makes it clear that the declaration about Branden Thornhill-Miller's "sympathetic attitude" towards religious claims is not meant to imply that he is a classical theist, but rather someone attuned to religious Universalism, in which case his own religious views may be consistent with the epistemology of religious belief advocated in this paper.
} 
belief, and their attempt at delineating the sphere of what they consider to be a clearly irrational epistemic stance, from the sphere where "it is not obviously unreasonable" (p. 47) to be religiously committed, is clearly genuine. Their restrictive approach to the justificatory grounds of religious belief may disappoint some defenders of the rationality of religious belief, but the vision of advocates of various metaphysical outlooks engaging in intellectually honest and genuinely philosophical - rather than merely rhetorical - debate, involving readiness to admit that there are objective limits to the strengths of the arguments supporting one's own position, may provide a model of a constructive atheism/religion debate.

There is, however, a second reason to look upon Thornhill-Miller's and Millican's project as innovative. It appears that the main rationale behind their going to such lengths to formulate their hypothesis of second-order religion, although none of the authors fully identifies with the metaphysical stance it entails, is that they find it less "dogmatic" and more "tolerant" than the first-order religions, "offering a more cooperation- and humilityenhancing understanding of religious diversity in a tense and precarious globalised age" (pp. 1-2). This explicit concern with the far-reaching existential consequences of fundamental beliefs, and the awareness how much may be at stake in the dialogue between adherents of various worldviews and religions, as well as the appeal to intellectual humility, make one think that here at last is a publication that might open a new chapter in the philosophical debate about doxastic pluralism, that is not primarily apologetic in nature, but focused on the relevance of pluralism for the global ethical discourse about the challenges facing humanity in the global age.

It is this latter, more universal concern about the possible contribution of the philosophy of religion to the global ethical discourse about the conditions of peaceful and solidary coexistence of people representing various metaphysical viewpoints, that prompts me to write this 'reply'. Consequently, this paper is conceived as a critical but ultimately constructive reflection on how Thornhill-Miller's and Millican's hypothesis might be refined to be made relevant in a way they themselves might wish it to be, since arguably in its initial formulation it is unlikely to appeal to broader spectrum of adherents of the first-order religions. Accordingly, in addition to pointing out to what I consider weak spots of Thornhill-Miller's and Millican's project, I will outline an alternative epistemological option of conceiving the nature and grounds of religious belief in a way that would accommodate their twin concern about the rationality of religious belief especially vis-à-vis religious diversity, empirical psychological research concerning religious experience, and the non-availability of conclusive 
evidence of 'perceived supernatural agency' - and with the challenge of religious diversity, while being a great deal less revisionist than their secondorder religion and showing that abandoning fundamental beliefs that are central to one's first-order religious tradition is not a prerequisite of holding a rational religious belief under the condition of religious pluralism.

This, as I will argue, can be achieved by attending to an axiologically grounded religious belief that I refer to as 'agatheism' or 'religion of the good' ('to agathon' in Greek), since it identifies the Ultimate Reality religiously conceived with the ultimate good which is postulated as a transcendental condition of our axiological consciousness through which we perceive and evaluate the goods at which our actions are aimed and towards which our hopes are directed. ${ }^{7}$ Agatheism conceives the Absolute as Agatheos ${ }^{8}$ by attributing to it first and foremost the characteristic of perfect goodness

${ }^{7}$ Speaking about the 'ultimate good' being postulated as a transcendental condition of our axiological consciousness I do not wish to imply that the epistemology of religious belief which I presuppose is identical with that of Kant, and that agatheism rests on the Kantian postulates of practical reason. Agatheism does not presuppose Kantian transcendental idealism, as it is supposed to be compatible with variety of metaphysical outlooks. More importantly, speaking about agatheism being grounded in axiology, I do not imply that it is Kant's 'moral argument' that provides the rational ground for agatheism. Unlike Kant, I do not presuppose that we need to postulate God's existence in order to make sense of morality. On the contrary, I assume that there are a number of satisfactory ways to make sense of our moral obligations towards other sentient beings, without recourse to God. Agatheism answers a different set of questions than questions about the foundation of morality, namely questions about the ultimate meaning of our finite existence as perceived through the lenses of our axiological consciousness which directs our thoughts and hopes towards some ultimate good which does not seem to be realisable in the physical universe. Thus the fundamental intuition behind agatheism has more in common with Plato, than with Kant. For this reason, in this paper I avoid the use of terms like 'moral' and 'ethical', because the term 'agathological' - which is a subterm of 'axiological' - points more accurately in the direction of the concerns from which agatheistic religious belief arises, and diverts attention from misleading associations with the Kantian 'moral argument' for the existence of God.

${ }^{8}$ The adjective 'agathos' is used to refer to God in the synoptic gospels in what may be considered to be a significant context. Encountering a 'rich man' who kneels before him and asks: "Good Teacher, what must I do to inherit eternal life?", Jesus objects to being called good, explaining that "No one is good but God alone" (oudeis agathos ei me heis ho theos) - in Mark 10:18 and Luke 18:19 the wording is identical. Also, the ancient Greeks used the phrase 'agathos theos' to refer to divinity. In one noteworthy example, in the second book of the Republic, when addressing the question whether it is appropriate to ascribe to god or gods responsibility for evil in the world, Plato argues that "god is, of course, good in reality and should be spoken of as such" (agathos ho ge theos toi onti te kai lekteon houtos - 379a9-b1), and that being good, god is unable to do harm or to be the cause of evil. 
(but not necessarily all the other attributes of God of the Western classical theism, since 'agatheism' it is a 'thinner' concept than 'theism', capturing the agathological core of a broad range of religious concepts of the Absolute). Most importantly, agatheism ascribes to the Ultimate Reality ${ }^{9}$ the function of being the ultimate ground and ultimate end (telos) of all that is good, thus making sense of the teleological and value-laden nature of our selfconsciousness, of our thinking about our existence as of self-conscious, rational and free persons whose actions are explained by reference to value-laden reasons, not merely to efficient physical causes. Thus agatheistic religious belief is grounded primarily in the considerations of the 'facts' about our own value-laden self-consciousness, and only secondarily in the considerations of the facts about the physical universe. As such, it locates itself in the proximity of the line of thinking about the Absolute represented by Plato, Augustine, Kant and Newman, but some of its distinctive features are shaped by the new awareness of the significance of pluralism of religious beliefs and value systems as a major challenge to a peaceful and solidary human coexistence in the global age.

Arguably, agatheistic religious belief so conceived is explicitly or implicitly presupposed in most first-order religious traditions as their doxastic core. As I will argue, such belief can be shown to be at least "not obviously unreasonable", while it can in turn ground other, more specific, beliefs of a given religious tradition, making its belief system - if internally coherent - rationally grounded. The fact of diversity of religious belief systems will be explained by postulating that religion is a space of the exercise of agathological imagination, i.e., this dimension of the faculty of practical reason which is intentionally directed towards the ultimate good (of no choice of ours) and guides our mental activity leading to value judgments by imagining and comparing alternatives as more or less optimal, relative to our sense of the good as a transcendental limetic concept). ${ }^{10}$ Various religious belief systems

9 Throughout the paper, I will treat the terms 'the Ultimate Reality' and 'the Absolute' as synonyms capturing in the most inclusive way the meaning of the Divine or highest reality that is the central focus of all religious traditions. Although the term 'God', reserved to capture the theistic conceptions of the Absolute, will also be used frequently, it is important to bear in mind that the conclusions of this paper are meant to be applicable as broadly as possible, to include all major religious traditions.

${ }^{10}$ I take the concept of the 'good' to be a transcendental concept in the Kantian sense as a form of our thought prior to experience of things which we perceive as having a property of goodness, and thus a concept that is primarily related to rational subject of perception, rather than intrinsically related to being. Following G. E. Moore, as well as the Medieval theorists of transcendentals, I take it to be a primitive, simple, first-known, and self-evident concept that cannot be analysed by taking recourse to a still higher genus. 
are thus taken to be the expressions of various visions of what their adherents consider to be the optimal ways of conceiving human potentialities vis-à-vis the Ultimate Reality as the ultimate good towards which their existence is directed. To put it differently, on an agatheistic account of religion, various religious belief systems are products of human agathological imagination, which guided by the fundamental religious belief identifying the Absolute with the ultimate good, searches for the optimal conceptualisation of the nature of the Absolute and its relation to the world and humanity, attempting to approximate the human view of the matter to the 'God's eye view'. As such, agathological imagination, as an imaginative dimension of reason, when active in the realm of religious belief, follows the logic of perfect being philosophy, especially the principle Deus semper melior - 'God is always better' [than we can imagine], imagining what kind of God or the Ultimate Reality would be greater, in the sense of 'more good', and what kind of relation between such God and the world would be consistent with the nature of God so conceived. What can make such a mode of deliberation something more than a purely fideistic exercise in utopian thinking, is linking it to the question of the teleological character of our axiological consciousness that is always directed towards some 'good', towards 'what ought to be', towards something that always transcends the facts about the physical universe ('what is'), and therefore cannot be explained by these facts alone, because it is not possible to derive values solely from the facts about the physical universe. Thus in order to make sense of the value-laden way we perceive reality as the world-for-us, and to give our existence some ultimate meaning, it may be necessary to postulate there being some ultimate good which is the ultimate source and the ultimate end of all that is good, and explains the teleological good-orientedness of our consciousness.

Needless to say, there will be various non-religious ways to conceive such 'ultimate good', thus making sense of our axiological consciousness without postulating the existence of the Ultimate Reality religiously understood (perhaps along the lines of non-religious Platonism that is presupposed

At the same time I take the concept of the 'ultimate good' to be a 'limetic concept' (from Latin limes - limit, frontier) by metaphorising the concept of a limes of a mathematical function as indicating a point towards which something tends in an asymptotic manner without ever reaching it. The concept of 'God' as 'Agatheos' is also a limetic concept. I stipulate that both in the case of the concept of the 'ultimate good' and the concept of 'Agatheos', the user of the concept presupposes that the reality to which the concept refers is only pointed to as the ultimate horizon that is of its nature unreachable for a human subject, although present as the background against which we perceive values that make their claim on us and are yet to be realised, as horizon is always 'present' when we perceive distant points on a trail that are yet to be reached. 
by some theoretical positions in the philosophy of mathematics, as well as in moral philosophy). Moreover, there is always a possibility of affirming the impossibility of 'making sense' of our value-laden perception of reality, opting, for example, for absurdism à la Camus. No doubt, various options may be articulated in an internally coherent way, and may be shown to be coherent with the facts about the physical universe established by science. The choice of an option how to make sense of our axiological consciousness will amount to a choice of a worldview. But since none of these options can be established conclusively as rationally superior, and yet considering various options in matters of such importance and taking a stance may be a psychological necessity, as well as a condition of living an 'examined life, choosing a religious option that identifies the ultimate good with the Absolute religiously conceived, may be as rational a choice as any. In any case agathological imagination will play a decisive role in choosing among the options, as well as among various religious conceptions of Agatheos as the source of ultimate meaning of human existence. Thus what we are left with is a range of 'agathological landscapes', conceived throughout human history by geniuses of agathological imagination, from philosophers and religious thinkers to poets and composers - agathological landscapes which we assess and choose between not for their aesthetic qualities, but for their goodness, goodness-for-us (agatheia).

In this paper I will argue that to the extent to which various first-order religious traditions have as its core agatheistic belief conceived in the way just outlined, they are in no way bound to be a breeding ground for irrationality or intergroup conflict. For this reason, agatheism may serve as a functional equivalent of Thornhill-Miller's and Millican's second-order religion, retaining its advantages, while avoiding its controversial aspects which may limit its appeal to adherents of first-order religious traditions. Unlike second-order religion, agatheism possesses conceptual resources to address the existential concerns that motivate and explain religious commitment concerns pertaining to the realm of subjects, not of objects, the realm of the first-person, not the third-person perspective, the realm of 'sense-making' and 'understanding' by reference to reasons and goals, not of proof and scientific explanation by reference to efficient causes. Moreover, agatheism does not depend on the evidence of 'perceived supernatural agency', neither is it based solely or chiefly on the Fine-Tuning Argument (although teleology is central to its logic), therefore its rationality is not conditional on the results of the empirical research of physicists or neuroscientists. For this reason, agatheistic belief, unlike Thornhill-Miller's and Millican's second-order belief, can be unconditional, rather than provisional, which in 
the case of a religious belief may turn out to be a psychological impossibility, since religious belief may require unconditional commitment.

Agatheism is grounded primarily in axiology, in the realm of values, not in the realm of facts about the physical universe, and therefore it cannot be conclusively confirmed or disconfirmed by scientific findings. Needless to say, in order to uphold its claim to rationality, religious belief as any belief worthy of respect has to be aligned with a worldview that is consistent with undisputed scientific findings, hence the importance of the philosophical work at the science/religion nexus, which, however, may only demonstrate the coherence of a religious worldview, not its veridicality, since of its nature no comprehensive worldview - whether religious or naturalistic - can be conclusively demonstrated to be true.

It is precisely this consideration, that religious belief grows out, as it were, of the ground of human values, of human concerns with 'what ought to be' or 'what might be', rather than solely with 'what is', which may provide a bridge between adherents of various worldviews, including atheists and theists, situating them epistemically on par. They are on par with regard to the rationality of their worldviews to the extent all worldviews contain a central component that has an axiological and teleological nature, and as such gives rise to questions regarding subjectively relevant meaning and conduct of human life which cannot be settled by natural science. However, such questions also cannot be left unanswered by adopting rigorously rational and consequently sceptical or agnostic attitude. As David Hume has conceded, to go on with our lives, and to make sense of our lives, we may have no option but to accept that the paradigm of objective rationality presupposed in formal sciences and natural sciences is not a universally applicable guide to human thought and conduct, and that in the sphere of practical rationality we are bound at least to some degree to rely on our natural instincts and imagination. As Thornhill-Miller and Millican point out, Hume referred to such grounds of our beliefs and actions as "irrational" (p. 5), but he might have been wrong on this point, considering what contemporary proponents of externalist theories of knowledge and cognitive scientists have to say about the functioning of our cognitive faculties and about the degree to which our cognitive processes remain unconscious. ${ }^{11}$ It may turn out that what Hume refers to as 'instinct' or

\footnotetext{
${ }^{11}$ This is not to say that Hume was not a farseeing thinker who more than anybody before him was aware to what degree the functioning of our cognitive faculties is nontransparent to reason. What he seemed to fail to realise was - to borrow Kant's phraseology - that the denial of knowledge in some areas of human intellectual pursuit makes space not just for potential intrusion of irrationality, but also for 'rational faith'
} 
'imagination', treating them as irrational, are in fact facets of the proper functioning of our complex cognitive faculties that ultimately aim at truth and thus are not irrational, despite the fact that we are not able to establish in an internalist fashion whether and to what degree the beliefs produced in such a way are warranted. Needless to say, we may need to admit that some such beliefs belong to the category of doxa, rather than episteme, to use Plato's distinction, accepting that episteme is just not available in the realm of thought that is existentially relevant.

This admission that in the existentially relevant areas of the exercise of human reason adherents of various worldviews are epistemically on par should facilitate constructive philosophical engagement of atheists and theists conducted in the spirit of intellectual humility and rational selfcriticism. While not being able to yield 'knowledge' in accordance with the methodological criterions appropriate for studying physical objects and exploring an objective point of view of a given matter, agathological intuition and agathological imagination as capacities of human reason may be considered respectable sources of inter-subjectively communicable and justifiable beliefs expressing a subjective point of view of the matter. As such, they may be conducive to contributing to the global 'ethical discourse' which - in the Habermasian sense of the term - focuses on the questions of the good life of individuals and groups cohabiting the same social space in the global age while having different life histories, traditions, and value systems, and being in need of finding a modus vivendi that would promote human flourishing of each and all individuals.

Presupposing such a 'dialogical' perspective, which Thornhill-Miller and Millican themselves encourage, I will grant them most of their empirically grounded arguments designed to challenge the evidential basis of the firstorder religions, while pointing to the axiological basis of religious belief which helps to shift the atheism/religion debate to the terrain where the partners of the dialogue can see themselves as epistemically on par. Thus I will concur that the kind of evidence Thornhill-Miller and Millican are looking for in 'empirical research' and searching for proofs of 'perceived supernatural agency' may indeed be unavailable. But at the same time I will suggest that availability of evidence so understood is not presupposed by religious believers, because what is decisive from their subjective point of view is a kind of moral certainty, or - better to say - agathological certainty,

understood not in religious terms, but as a commitment to a principle of hope that teleology which characterises our axiological consciousness is a reliable guide for our sense-making activity without which human agency would be unintelligible, as already Plato has noticed. 
which - unlike empirical certainty concerning our knowledge of the facts about the physical universe - is grounded (and hence not groundless) in the realm of values.

Like moral beliefs, religious beliefs are formed in connection with thinking about human good, and in this sphere nothing more than agathological certainty, plus coherence of one's worldview, may be expected and demanded. Agathological certainty as a state of mind has a certain phenomenal quality which is a source of subjective reassurance, and can be captured by the adjective 'agathonic', created by conjunction of 'agathon' and 'the tonic' - a musical term referring to the central tone of a scale that is perceived subjectively by a listener as the point of 'departure' and 'arrival' of a tonal musical narrative, and thus as a kind of telos and the point of psychological rest. Thus the word 'agathonic', metaphorising the musical 'tonic', takes on a meaning of 'rest of the mind in the good', or 'rest of the mind in the confidence of reaching the good, realising the good, or being directed towards the good.12 Certainty specific to religious beliefs, like certainty specific to moral beliefs, may be perceived subjectively and shared inter-subjectively, but cannot be turned into an objective certainty, and therefore the search for such certainty - whether through the Fine-Tuning Argument or by reference to evidence of 'perceived supernatural agency' - is bound to be futile.

\section{SECOND-ORDER RELIGION: DISPUTING THE NATURE AND GROUNDS OF RELIGIOUS BELIEF}

As indicated in its title, Thornhill-Miller's and Millican's paper is above all devoted to outlining "the limits of rational religious belief", focusing on "perceived supernatural agency" as "the predominant evidential influence on religious belief" (p. 2). As the discussion about the unavailability of the appropriate evidence proceeds, it becomes clear that it will be necessary to raise the question of the nature of religious belief that depends on the nature of the subject matter of belief, keeping in mind what Aristotle has observed in his Nicomachean Ethics: "It is the mark of an educated man to look for precision in each class of things just so far as the nature of the

12 This agathonic sense of 'rest of the mind in the good' that accompanies our mental states of certainty in the sphere of moral and agathological beliefs is analogical to the sense of 'rest of the mind in truth', which accompanies our states of certainty in the realm of beliefs about existentially irrelevant facts of the matter, but unlike in the case of certainty about factual beliefs and also aesthetic beliefs, certainty about moral and agathological beliefs carries with it a sense of fulfilled obligation and is specific to this category of beliefs. 
subject admits; it is evidently equally foolish to accept probable reasoning from a mathematician and to demand from a rhetorician scientific proofs." ${ }^{13}$ In a similar fashion one may argue that it may turn out to be unreasonable to demand irrefutable proofs and conclusive evidence in the realm of religious belief.

\subsection{Grounds of religious belief: A priori considerations}

To begin with, one can argue a priori against the availability of proofs or conclusive arguments regarding God's existence, since the very concept of such proof or conclusive argument appears to be incoherent, as by definition God transcends human concepts, hence what is being grasped in human concepts which are applied to God cannot be God as God really is. Therefore theistic arguments may at most serve as 'pointers' (like the finger pointing at the moon in the oriental metaphor discussed by Thornhill-Miller and Millican, to which we will later return), or 'paths' (perhaps like Aquinas' viae) that may direct human thought towards God, without 'reaching' God, because the concept of God itself - involving such qualifications as 'perfect' or 'infinite' - stipulates that God as God really is, is out of reach of the human mind. Only Divine mind can grasp God, thus arguing for the existence of the referent of a human concept of God, one cannot conclusively establish the existence of God.

Even more obviously, conclusive public empirical evidence of Divine agency is impossible, because there is no way one could deduce from finite effects the existence of an infinite Divine cause, while the conclusive evidence of the agency of finite 'supernatural' agents, even if available, would be useless from a theistic point of view, because from the existence of finite agents - whatever their nature - one cannot deduce conclusively the existence of a theistic God. Thus the kinds of evidence that are discussed by Thornhill-Miller and Millican, such as "reported miracles, religious experiences, and other instances of perceived supernatural agency" (p. 2) are bound to constitute unsuccessful evidence, unless considered in connection with the pre-existing theistic belief, in which case it will be thought of as an 'evidence' in an entirely different sense, namely not as an evidence of God's existence or ability to act in the physical universe, but as a source of reassurance in a belief - e.g., in God's providential care - already firmly held by a believer on a different ground. ${ }^{14}$

${ }^{13}$ The Complete Works of Aristotle: The Revised Oxford Translation, ed. by Jonathan Barnes, 2 vols. (Princeton, NJ: Princeton University Press, 1984), Book I, 1094.b24.

${ }^{14}$ Since Thornhill-Miller and Millican devote much space to the discussion of the evidential value of reported miracles, it is important to keep in mind that extraordinary 
Does it mean that the entire philosophical enterprise known under the heading of 'arguments for the existence of God' rests on a mistake, and atheists waste their time attempting to refute them? It certainly does seem so, if terms like 'proof' or 'conclusive argument' are used in this context, and are intended to mean something akin to how such terms are understood in 'hard sciences', where a proof or argument can be said to be conclusive when every person who is able to understand it will recognise it as such. However, it is likely that the pre-modern authors who - like Aquinas - are taken to be constructing arguments for the existence of God, do in fact seek to show coherence of the worldview of religious believers, that is to show that their religious beliefs do not contradict other well-established beliefs about the world and the place of humanity in it, which a reasonable person might be expected to hold. Such interpretation would be consistent with what seems to be implied in the phrase fides querens intellectum, which has been used by medieval philosophers to refer to this kind of employment of reason in the realm of religious thought. What we are having here is thus two very different kinds of reasoning about God: one which the critics of theistic arguments (and some of their apologetically inclined opponents) have in mind, and the other presupposed by the likes of Aquinas and employed implicitly by religious believers. The first one is a reasoning which starts with the facts about the world as explanandum and ends with God as explanans, without presupposing in the point of departure any particular concept of God. As I have just pointed out, such argument can never be successful, because the facts about the universe are always such that it will suffice to posit a finite cause to explain them, therefore what will be posited as explanans, will always be less than God.

The second way of understanding what 'theistic arguments' are really about is that they aim at showing how beliefs about God - whose concept is presupposed, not argued for - can cohere with beliefs about the world. When forming the concept of God or the Ultimate Reality as perfect, infinite, etc., humans could not have relied solely on the reasoning that is aimed at explaining facts about the universe, but instead they had to rely primarily on

events described in the ancient texts referred to as 'miracles' in modern times could not be conceived as playing the role of an epistemic evidence that Hume and ThornhillMiller and Millican are disputing, because such events would be perceived against the background of an entirely different view of nature (with the existence of God or gods taken for granted, with no distinction between the 'natural' and 'supernatural' realm, and thus with the antecedent probability close to 1 that a miracle may happen), therefore it may be an anachronism to ascribe to the biblical authors or other ancient authors an intention of pointing to 'miracles' as proving or providing evidence for the existence of God or gods. 
the reasoning aimed at explaining 'facts' about the way we think about the world and ourselves - as valuable, as bearer of values - and only secondarily on the reasoning aimed at explaining facts about the universe (secondarily, but necessarily, because without reference to the world we cannot form any concepts and think about anything, least about God). That this is what Aquinas is in fact doing in his Quinque Viae seems evident from the way he injects at the crucial stage of each 'journey' from the world to God, just before reaching the conclusion, a formula: "and this is what we call God", ${ }^{15}$ thus referring to a set of beliefs about the nature of God that is tacitly presupposed and must have an independent ground, because nothing in the preceding steps of each of his 'arguments' grounds a full-blown concept of a theistic God. Perhaps, in order to avoid confusion, and not to tempt atheistic critics to waste their time on showing that the 'theistic arguments' are inconclusive, it might be helpful to reformulate them all, so that they would begin with Aquinas' formula: 'Since this is what we call God ..., then moving to the facts about the world and arguing that God so conceived may play the role of the Unmoved Mover, the First Cause, the Designer of the universe, etc., and concluding that therefore the facts about the world do not contradict the possibility of the existence of God so conceived. Indeed, they show that the belief in God so conceived has certain explanatory potential, which explains why the human mind has a tendency to 'travel' these 'five paths' from the world to God so conceived, although such 'journey' is possible only because the concept of God is there in the mind of the 'traveller' at the beginning of the 'journey'.

From the above discussion of the necessary inconclusiveness of theistic arguments and of the impossibility of successful empirical evidence of perceived Divine agency, there follows a number of consequences relevant to the assessment of Thornhill-Miller's and Millican's project. Firstly, in order not to be groundless and therefore irrational or non-rational in some fideistic fashion (which we do not advocate in this paper), religious belief has to have some ground, but neither theistic arguments, nor any public, empirical evidence one can think of, may ground a belief in God or the Ultimate Reality religiously conceived and involving qualifications such as 'perfect,' 'infinite', etc. ${ }^{16}$

${ }^{15}$ See Thomas Aquinas, Summa Theologiae, Fathers of the English Dominican Province, trans., ed., and corrected by faculty and staff of the Aquinas Institute (Lander, Wyo.: The Aquinas Institute, 2012), Part I, q. 2, art. 3.

${ }^{16}$ The tradition of scepticism about human ability to ascribe theistic attributes to the Absolute on the basis of our knowledge of the facts about the physical universe (rather than our awareness of our fundamental orientation towards the good) has a line of prominent exponents, from Plato, through Augustine, up to John Henry Newman 
Secondly, the Fine-Tuning Argument cannot provide sufficient justification for religious belief any more than any other theistic argument. Whatever the verdict of future physics may turn out to be regarding the apparent 'anthropic coincidences', the Fine-Tuning Argument cannot ground belief in a theistic God, because an atheist will always have an option of positing that something else than God, that is, something less than God, may serve as explanans of the observed order of the universe. The most such an argument may establish is a belief in some Designer of the order of the universe, but not the creator in the sense of the ultimate source of all being and value, a perfectly good and holy God worthy of worship, ${ }^{17}$ who can serve as the ultimate anchor of human hope. ${ }^{18}$

Therefore, thirdly, the only way to ground specifically theistic or agatheistic religious belief, a belief in God or the Ultimate Reality endowed with moral or - better to say - agathological attributes, ${ }^{19}$ is by reasoning from human axiological consciousness to God as the ultimate good, towards which human axiological consciousness is ultimately directed.

However, fourthly, once a belief in God as the ultimate good is so grounded, there is a possibility of a 'justificatory descent', so that, for example, belief in God being the ultimate source of all that exists, or belief in God 'revealing' himself to (some) rational creatures, may now be grounded in the foundational belief in God being perfectly good and being the

who famously stated: "Were it not for this voice, speaking so clearly in my conscience and my heart, I should be an atheist, or a pantheist, or a polytheist when I looked into the world." (J. H. Newman, Apologia Pro Vita Sua (London: Longmans, Green, and Co., 1908), p. 241.)

${ }^{17}$ Actually, the Demiurge of Plato's Timaeus that may serve as an example of such a postulated explanans of the order of the physical universe is considered to be a malevolent, rather than benevolent being. Similarly, Hindu cosmologies do not ascribe to the gods responsible for 'shaping' of the material world the attributes of the Ultimate Reality.

${ }^{18}$ Interestingly, Thornhill-Miller and Millican are aware of this inability of the FineTuning Argument to point towards morally perfect designer of the universe (cf. footnote 144 on p. 47), yet they stop short of recognising that this limitation is in fact fatal to their project, given that they identified it as the only rational basis of their second-order religion.

${ }^{19}$ Speaking about 'moral' attributes of God may be problematic, given that the term 'moral' is usually associated with 'moral obligations', while attributing to God any 'obligations' which God would need to fulfil to be 'moral' may be incoherent. We usually apply the term 'moral' to God when speaking about God's attributes which are related to creatures, namely about the ways God may be good-for-us. Thus it seems that in this context the use of the term 'agathological' is preferable to 'moral', because the former does not carry with it the sense of 'moral obligation'. 
ultimate good, which makes it reasonable to believe that God so conceived might be expected to be in such and such relation to the world and humanity. Thus the doxastic structure of an agatheistic religious belief system that is grounded in axiology can be metaphorically envisaged as a ladder, but with descending, not ascending order of justificatory dependence, and the ladder hangs, as it were, from the 'ceiling' of the belief in God being perfectly good and being the ultimate good. On this picture, religious beliefs of increasing particularity will draw their justification from the higher-level beliefs, being perceived as more or less rational against the background of antecedent probability of something being the case, given that we have accepted the higher-level belief as true. Thus we may speak about antecedent probability of Divine self-revelation or religious experience, relative to the higher-level belief in perfect goodness of God, which will play the role of the justificatory basis of particular beliefs grounded in one's religious experience or in one's encounter with what one considers to be a case of Divine revelation. The key point is that such beliefs without the basis in antecedent probability of the relevant higher-level beliefs could not be justified solely by reference to the experience that grounds it. Hence, particular religious experience may constitute a ground of beliefs formed on its basis, but both subjective certainty regarding the veridicality of the beliefs grounded in such experience and inter-subjective justification of such beliefs are dependent on the antecedent probability of the higher-level beliefs, and without holding these higher-level beliefs a religious experience could not be even recognised as such by the subject of the experience. What will be important to bear in mind accepting such a vision of the epistemology of religious belief, with the principle of justificatory descent as its centrepiece, is that if the entire agatheistic doxastic practice depends for its justification on the belief in God being perfectly good and being the ultimate good, then any religious belief that will stand in clear contradiction to these assumptions regarding the nature of God - and to any consequences that may be drawn from this foundational agatheistic belief - will rightly be considered as positively irrational. ${ }^{20}$

${ }^{20}$ In this vein, I have argued elsewhere that a belief in 'Divine favouritism', whether it comes to an exclusivist view of the truth about the Ultimate Reality being available to adherents of only one religious tradition, or to an interventionist vision of God changing the natural course of events to assist some creatures more than others in their realisation of their creaturely potential, is inconsistent with the logic of perfect being philosophy that underlies the exercise of agathological imagination, and makes a religious belief system that includes such beliefs internally incoherent. (Cf. Janusz Salamon, "Theodicy of Justice as Fairness and Sceptical Pluralism”, in S.T. Kolodziejczyk and Janusz Salamon (eds.), Knowledge, Action, Pluralism (Frankfurt am Main: Peter Lang Press, 2013), pp. 249-280.) 
Fifthly, as is entailed in what was said above, acknowledgment that no experience or event in the physical universe may serve as conclusive evidence of the existence of God, or of perceived Divine agency, does not imply a denial that religious experience - understood in terms of various modes of awareness of the Divine presence - does play a central role in religious life understood as a spiritual journey towards God which consists in realisation of values that have its source and fullness in God. In such a connection, instances when a religious believer forms a belief that she has experienced God as being present to her do not play a role of 'evidence' of God's existence that would give rise to a belief in God's existence that was not there. Instead, such experiences typically occur in the context of a process of spiritual development or metanoetic transformation (the Greek noun 'metanoia' signifying a change of mind - in the biblical vocabulary acquires more specific meaning of 'conversion' as turning towards God). In such a context, religious experiences have spiritual progress rather than epistemic certainty for their purpose, therefore they presuppose and probe faith and trust in God, rather than allowing one to turn God into an object of experience which might be 'objectified' or 'pinned down' to ensure a degree of epistemic certainty on the part of the subject of experience. If any conclusion regarding the evidential value of religious experience can be drawn from philosophical analysis of the mystical literature, it is that the 'object' of religious experience tends to evaporate, as it were, when approached as an object, in an objectifying way, rather than as what it is supposed to be, namely a subject par excellence: a supremely free Absolute Mind, transcending infinitely the limitations of human mind. Even in the case of the human inter-personal encounters, it is not possible to fully objectify the subjectivity of the other, and speaking about religious experience we are faced with epistemological riddles similar to those associated with 'experiencing other person', except that when the 'object' of the experience is supposed to be the subjectivity of God, the challenge is infinitely magnified by what we stipulate about the nature of God.

Accordingly, in most religious traditions - even when the Ultimate Reality is not conceived as a person - mystical encounter with the Ultimate Reality is usually conceived in terms of free gift of self-disclosure on the part of God, not something that can be 'achieved' by human effort, and this is not contradicted by the existence of mystical 'traditions'. Such traditions do not presuppose some kind of 'objective availability' of God to be experienced under clearly specified conditions, and do not teach how to 'achieve' the experience of God by following some esoteric manual, but instead advise the adept how to remove the obstacles to encounter with God - obstacles consisting in inappropriate 'objectifying' and 'possessive' attitude towards 
God. Thus, while being in principle sympathetic to Thornhill-Miller's and Millican's proposal "to embrace the universality of these [religious] experiences, interpreting them as pointing toward the divine in a way that is accessible to those of all faiths" (p. 19), I would need to point out the a priori and a posteriori considerations which must qualify this "universality" as implying possibility of 'authentic' religious experience taking place in the context of "all faiths", but not some kind of 'general accessibility'.

Taking it all into account, one can conceive of religious experience in a way that is consistent with the agatheistic concept of God or the Ultimate Reality as the ultimate good, namely as an intellectual perception, by a subject that conceives of God or the Ultimate Reality as supremely good, of the presence of a reality apprehended by the subject as exceedingly good and identified by the subject as God or the Ultimate Reality. There is no place here to engage in a discussion about the causal part of the story of the subject of religious experience forming such a belief, but it goes without saying that such experience cannot serve as a public and conclusive evidence of God's existence or agency. However, from the point of view of the subject of such experience, a belief formed on its basis may be rational to the extent it is supported by the higher-order belief in God as the ultimate good that might be expected to make his presence felt to a believer who "seeks his face", to use a biblical expression (Psalm 24). As in the case of every experience, its subject forms on its basis beliefs characterised by subjective certainty, but in the case of religious experience it will be the kind of agathological certainty defined above, underpinned by agathonic feeling of 'rest in the good', which reassures the subject in his confidence in the authenticity of an experience precisely because of its positive content. As is clear from countless reports of such experiences, the 'object' of such experience presents itself to the subject as exceedingly good, but to make any sense of such 'experience', one has to presuppose that the subject has a particular concept of God or the Ultimate Reality before having an experience of its presence. This principle applies to any experiential data that may be taken to be a manifestation of God's existence or action in the world, which reinforces our conclusion that theistic religious belief cannot be based solely on a theistic argument that starts with the facts about the physical universe, as does the Fine-Tuning Argument on which Thornhill-Miller and Millican want to base their second-order religious belief.

\subsection{Grounds of religious belief: A posteriori considerations}

So far we dwelt chiefly on the a priori considerations, related to the nature of God as stipulated by religious believers, relevant to the assessment of 
Thornhill-Miller's and Millican's critique of the rationality of first-order religious belief that presupposes that the classic theistic arguments on one hand, and religious experience and miracles on the other, exhaust the list of possible sources of rationality of religious belief. However, there is another set of considerations, this time a posteriori, related to the nature of religious belief as fulfilling certain functions in the life of a typical religious believer, and thus explaining why such a believer holds any religious beliefs at all, whether rational or not. These considerations will be relevant especially to the assessment of the positive aspect of Thornhill-Miller's and Millican's project, namely their hypothetical second-order religion. Both sets of considerations will be decisive for putting forward agatheism as a functional equivalent of second-order religion, suggesting that agatheism scores better on all counts.

My critique of Thornhill-Miller's and Millican's hypothesis boils down to a worry that their concern with the emancipation of religious believers from irrationality leads them to adopt a paradigm of objective rationality appropriate for natural sciences that considers only the factors that are objectively verifiable, while ignoring or explaining away what following Thomas Nagel we might call 'the subjective point of view of a subject matter'. As a result they end up throwing the proverbial baby out with a bathwater and hypothesise a form of religious belief that arguably lacks what is religious in religion.

What is at stake here is not some purely academic definitional disagreement (what we are supposed to mean by 'religion'), but something absolutely central to Thornhill-Miller's and Millican's project, given that they start with admission that the 'secularization hypothesis' appears to be wrong ("as religious influence reasserts itself around the world"), then delve into psychological research, which supposedly "discovers why supernatural thinking is so intuitive and so hard to eliminate even when the effort is made" (p. 44), and finally proceed to propose a more rational replacement to the actual forms of religious belief to which people adhere to. Thus in the heart of this enterprise lies the question: what makes people adhere to religious beliefs in the first place, despite their growing awareness that natural sciences explain the facts about the physical universe without reference to supernatural powers?

Unsurprisingly, psychological research, which Thornhill-Miller and Millican bring to bear on their discussion of the above question, effectively explains away what religious scholars and believers themselves might consider to be specifically religious elements in religion, by reducing the reasons why people become or stay religious to "various practical benefits 
of religion to the individual - social support, sense of meaning and security, comfort in times of grief, prayer-placebo". Taking into account that such "benefits" of religious belief might perhaps "equally well be delivered by non-supernatural means (e.g. non-religious group membership and forms of meditation, psychotherapy, etc.)", Thornhill-Miller and Millican are nevertheless inclined to think that "the very naturalness of religion gives some reason to doubt its easy replaceability, historically immersed as we are in well-established religious traditions whose rituals have evolved to fit human needs" (p. 45). It is the way they define these "human needs", the satisfaction of which is supposed to explain the existence of religion, that is perhaps the most disputable aspect of their work, while being of crucial importance, because it shapes their view of the character and nature of religious belief, which in turn colours their second-order religion. It is my contention that Thornhill-Miller and Millican overlook or downplay the importance of a number of fundamental aspects of religious belief, such as (a) its soteriological/eschatological perspective presupposing some formulation of "what can I hope", to use Kant's phrase; (b) its metanoetic/ transformational function presupposing some paradigm of spirituality which goes beyond the search for "sense of security" and "comfort in times of grief"; and (c) its relational/inter-subjective character associated with religious attitude of worship and love, and presupposing freedom of assent. By ignoring these central dimensions of religion, they make both their discussion of the limits of rational religious belief and the plausibility of their second-order religion hypothesis open to dispute.

Before discussing the importance of the fundamental aspects of religious belief enumerated above to the assessment of second-order religious belief, and of agatheistic belief as its possible contender, let me draw attention to a startling fact that to the extent second-order religion is based solely on the Fine-Tuning Argument and detached from first-order religious traditions, it is hard to see how it could deliver even these narrowly defined "practical benefits", like "social support, sense of meaning and security, comfort in times of grief, prayer-placebo", which our authors identify as the probable motivation that explains religious commitment. Thus there seems to be an internal tension between what the authors themselves identify as the human needs that religion is supposed to satisfy and their articulation of their second-order religion which they put forward as a satisfactory replacement of the existing religions, while it is clear that these needs cannot be met by second-order religion so conceived (and things will get worse when we will agree that religious belief typically satisfies also other important "human needs" which Thornhill-Miller and Millican do not take into account). 
The reasons why second-order religion cannot satisfy such existential needs have to do with the inability of the Fine-Tuning Argument to establish a belief in God or the Ultimate Reality that might satisfy them. The authors do not make it clear what particular religious beliefs the Fine-Tuning Argument is supposed to justify, but it is clear what kind of beliefs cannot be justified by it. The older versions of the Teleological Argument were supposed to lend its support to belief in the existence of a Designer accounting for the total order of the universe, therefore arguing from the effect to the cause, one might have been able to 'learn' a lot about the Designer of the universe as the cause of its order. But precisely for this reason, it was possible to question the Teleological Argument by pointing to the elements of apparent disorder in the universe (as did Hume), or to the inability of the human mind to grasp the architecture of the universe in its totality in such a way as to be able to affirm the order that would call for explanation by reference to a rational Designer (as did Kant). Moreover, both Hume and Kant have argued that even if it would be possible to affirm the order of the universe that would point to a Designer, it would be problematic to ascribe to that Designer the typical theistic attributes, and perfection in general. The universe is not perfect, so its Designer does not have to be perfect, and the existence of evil makes it less than obvious that the Designer of the world in which we live must be perfectly good. The Fine-Tuning Argument differs from the earlier versions of the Teleological Argument in that it specifies in a more precise and scientifically verifiable way the elements of the order that call for explanation (namely certain 'anthropic coincidences' in the laws of physics without which higher life forms could not develop), however it retains the other limitations of the Teleological Argument which prevents one from concluding that the Designer responsible for setting the physical constants needs to be the perfect and omnibenevolent God of theism.

Quite apart from the unsuitability of the Fine-Tuning Argument as a candidate for the sole foundation of a religious belief system having to do with its provisional nature (since future physics can always explain this or that physical constant undermining 'supernatural' significance of all other 'anthropic coincidences'), the argument does not show that the Designer of the universe may be concerned specifically with the human species. For this reason Thornhill-Miller's and Millican's following interpretation of what the Fine-Tuning Argument implies - an interpretation on which the entire argument of the paper appears to rest - seems problematic in more than one way. They write: "If the universe has in fact been finely tuned to be especially conducive to the evolution of higher life forms with moral and 
religious sensitivities, then it is only to be expected that such life forms will proliferate across the multitude of galaxies we observe, and that religion will evolve in many different ways, yielding a wide variety of specific religious systems" (p. 4). Firstly, the above sentence appears to imply that the authors take it for granted that fine-tuning entails that what explains the fine-tuning, explains also the evolution of the species, but this is surely reading into finetuning more than the apparent discovery of the physical constants which are 'life-friendly' justifies. But let's presume that it is reasonable to make the connection between fine-tuning and the evolution of the species, perhaps by suggesting that once we have granted that the postulated Designer of the universe is in some sense rational, we may reason that it would be pointless to fine-tune the universe to make it hospitable for life, without setting the conditions for evolution of the higher forms of life. It will still be far from obvious, why the Designer in question would aim at the evolution of the life forms with "moral and religious sensitivities". Most importantly, even if one would grant Thornhill-Miller and Millican that the Fine-Tuning Argument establishes rationality of belief in the Designer's special concern for the development of rational creatures like human beings, nothing would follow when it comes to the question whether the Designer of the finely-tuned universe is concerned about Jones' or Smith's existence. Thornhill-Miller's and Millican's comment about proliferation of higher life forms across the universe, their evolution "in many different ways", and development of a wide variety of religious systems suggests strongly that they presuppose that the Designer set certain initial conditions that make the evolutionary processes leading to the development of higher life forms possible, but the entire process is random, therefore there is no point in talking about the Designer being 'providentially' concerned with this or that form of the higher life form (like humanity), not mentioning Jones or Smith.

How against this background one is to understand the suggestion that part of the design manifested in fine-tuning is to make all these higher life forms evolving in many different ways end up with "moral and religious sensitivities" is a mind-boggling question. One is tempted to suspect that what is happening here is Thornhill-Miller and Millican realising that it is hard to make the logical connection between the existence of the Designer of the finely-tuned universe and the existence of "religious sensitivities" in humans, and salvaging the situation by bringing through the back door the more expansive old version of Teleological Argument, in which the Designer is supposed to explain all important features of the universe.

One's suspicions that this is indeed the case grows when towards the end of the paper, at the culminating point of their presentation of the 
virtues of second-order religion, Thornhill-Miller and Millican appeal to 'religious instincts' (presumably synonymous with 'religious sensitivities' just mentioned), and apparently intend to make much out of this purported instinctual religious faculty, while it is not clear how this faculty fits in a coherent way a broader picture of the epistemology of religious belief which the authors seem to presuppose throughout the paper. As if realising how limited in content second-order religious belief based solely on the Fine-Tuning Argument is likely to be, and therefore it needs to be somehow supplanted, they propose "to abandon the competing dogmatisms of firstorder supernaturalism and instead fall back onto an undogmatic version of its second-order cousin, finding intimations of divinity in the general structures of the world and in our own religious instincts, while remaining fully committed to the enterprise of natural science" (p. 46).

Now, there are at least two ways how 'religious instinct' may be understood in the context of Thornhill-Miller's and Millican's project, both of which are problematic. A rigorous interpretation of 'religious instinct' is likely to be theologically impotent, while an unrigorous interpretation is likely to cause a theological flood which our authors may wish to resist. Thus, either 'religious instinct' is conceived here in the way that finds support in the Fine-Turning Argument itself, in which case it cannot imply more than instinctual tendency to recognise the existence of the Designer about whom there is no reason to believe anything else than that 'he' set the physical constants in a way that is conducive to the development of higher-life forms, in which case it is hard to see what kind of "intimations of divinity" might be found by appeal to such instinctual faculty. Or else 'religious instinct' can mean as much as is implied in Calvin's concept of sensus divinitatis employed by Alvin Plantinga in his influential externalist and anti-evidentialist Reformed epistemology. Sensus divinitatis, a kind of sixth sense, 'religious sense', is indeed a form of 'religious instinct' and is understood to be a part of the design of our cognitive faculties by God the Creator, and is universal, and thus in a certain sense 'natural', independent of tradition-specific religious revelation, hence it might play the role of 'religious instinct' that Thornhill-Miller and Millican postulate. But the way sensus divinitatis is understood in Reformed epistemology shows that 'religious instinct' does not have to be conceived in a minimalist way that could be justified by the Fine-Tuning Argument. On the contrary, this instinctual faculty is taken to be a belief forming mechanism which - using Plantinga's terminology - when functioning properly and in an appropriate environment confers warrant on all sorts of particular religious beliefs 
giving them a status of warranted beliefs. ${ }^{21}$ Needless to say, adherents of wide variety of theistic religious traditions might in a similar way claim warrant by thinking about their religious beliefs as being formed by this instinctual belief forming mechanism, in which case we are back with plurality of fullblown first-order traditions, the rationality of which Thornhill-Miller and Millican deny.

No less controversial is the suggestion that we may find "intimations of divinity in the general structures of the world", given that on its own, the Fine-Tuning Argument does not prove that the Designer of the finelytuned universe must be conceived as 'divine', and stipulating the concept of 'divinity' in a way that would allow for such a move would have to be justified on a ground independent of the Fine-Tuning Argument.

By now it should be clear how much depends on which of two ways of approaching the issue of fine-tuning - rigorous or unrigorous - will Thornhill-Miller and Millican adopt. They may choose to construe the FineTuning Argument in a rigorous manner, but then it will entail at most the existence of a Designer who ordered the universe in a way that is conducive to the existence of life in it (needless to say, 'he' does not have to be the universe's creator, and even less so a creator ex nihilo). Such a conclusion might perhaps be a source of confidence in the general teleology of the physical universe and thus may reassure those who find it difficult to accept that the universe is an outcome of some unintended nexus of physical causes. However, there is little reason why it should be taken to justify a confidence in the Designer intentionally bringing about the existence of creatures with "religious sensitivities", and no reason to believe in the Designer's providence in safeguarding the well-being of any particular life forms, or individuals.

The alternative approach to fine-tuning may be to argue that fine-tuning justifies going back to the full-blown Teleological Argument which treats God - whose concept is drawn from a different source than the Teleological Argument itself - as explanans of all sorts of phenomena which appear to have teleological characteristics, including the existence of "moral and religious sensitivities" and everything that the existence of such sensitivities might imply. Such an option is available, but only to those who wish to accept the epistemology of religious belief I have recommended above, involving the principle of justificatory descent, since now someone who already has a concept of a theistic or agatheistic God grounded in axiology, confronted with the alleged 'anthropic coincidences' will be able to form a belief that the conclusions of the Fine-Tuning Argument, when read against the

${ }^{21}$ Cf. Alvin Plantinga, Warranted Christian Belief (Oxford: Oxford University Press, 2000), pp. $148 f f$. 
background of the higher-order theistic beliefs make sense, because their antecedent probability relative to the higher-order beliefs makes them, as well as the conclusions of the more expansive version of the Teleological Argument, reasonable. That would be an example of unrigorous approach to fine-tuning, which leads to drawing conclusions which are not entailed in the Fine-Tuning Argument standing on its own.

It seems that Thornhill-Miller and Millican intend to approach finetuning in the rigorous way, but realising that their second-order religious belief is empty of content, or nearly so, they find themselves under pressure to base their second-order religion on the old-style expansive Teleological Argument, rather than on the modern Fine-Tuning Argument rigorously interpreted. However, Thornhill-Miller and Millican have good reasons to resist this kind of unrigorous approach to teleology, because it is precisely this line of reasoning which in response to the question: 'what was God's telos in creating the universe and human beings', generates the entire firstorder theistic religious traditions (relying in the process on agathological imagination). After all, once we have granted that the Designer of the universe transcends nature, and the Designer is responsible for all important features of the universe, why not presuppose that the ultimate telos of the creation transcends nature? If God the Designer is responsible for the existence of "higher life forms with moral and religious sensitivities", which direct their thoughts and hopes towards God or the Ultimate Reality that transcends nature, what is unusual in presupposing not just a particular teleological vision of history involving the 'communication' of God with his creatures, but also a particular eschatology, a vision of the end-state, that transcends nature? One might presume that faced with the question: what is the telos of the existence of these "higher life forms with moral and religious sensitivities", Thornhill-Miller and Millican might wish to answer as Aristotle would: flourishing life within the bounds of nature. But in such a case, why would the Designer of the universe bother to endow such creatures with "religious sensitivity" that tends to direct their thoughts and hopes beyond the bounds of the natural and beyond death?

Thus, if one adopts an unrigorous approach to fine-tuning allowing ourselves to discern teleology in various spheres of reality (rather than limiting oneself to the list of 'anthropic coincidences'), one risks opening the doors to a theological flood that results in a multiplicity of first-order religious traditions that may actually be conceived as alternative detailed responses to the question about the ultimate telos of all that exists, and this is an outcome that Thornhill-Miller and Millican want us to avoid. And yet, were they to stick to the rigorous interpretation of fine-tuning, they would be unable to 
explain how a religious belief based solely on the Fine-Tuning Argument may be a source of the alleged "practical benefits" of religious belief to the individual, such as "social support, sense of meaning and security, comfort in times of grief, prayer-placebo" (p. 45). If there is no reason to believe that the Designer of the finely-tuned universe ought to stretch out 'his' providential care over humanity at large and even less so over individual human beings, how might accepting (provisionally) the hypothesis that fine-tuning points to some Designer responsible for setting certain physical constants cause one feel "comforted in times of grief" or have a "sense of security"? And what reason might the Fine-Tuning Argument give one to think that it might make sense to pray to such a Designer of the finely-tuned universe? As to possible "social support" as a "practical benefit" of religious belief, it is hard to think what might bind together adherents of such second-order religion to create a religious community that might provide its members with "social support" that could not be easily replaced by social support of non-religious kind. One may safely presume that the "social support" found by religious believers in the context of their religious communities has some specifically religious component, such as companionship on the path of religious growth defined against the background of some shared spiritual and soteriological vision.

It is a pity that the phrase "sense of meaning" that appears on ThornhillMiller's and Millican's list of the alleged "benefits" of religious belief has been left by the authors without any comment that might give us a clue what it is supposed to imply. On the agatheistic picture of religious belief, satisfying our human need for making sense of our first-person, irreducibly subjective point of view on existentially relevant aspects of the world is - next to the need of making sense of our axiological consciousness - one of the main motives which give rise to religious belief. However, if Thornhill-Miller and Millican would stick to the rigorous interpretation of fine-tuning, it is hard to see how their second-order religious belief might be an abundant source of existentially relevant "meaning".

Perhaps the first sphere of meaning which comes to mind in connection with religion is giving each individual existence an ultimate meaning despite vast majority of lives lived in the course of human history having all appearances of abject failure, of good being defeated, of hope being denied. For this reason, all post-Axial religious traditions, even the ones which lack a God-figure, presuppose some possibility of ultimate fulfilment of human potential by way of transcending the limitations and contingency of our present condition. Whether conceptualised in terms of salvation, redemption, liberation, or in some other way, this soteriological 
and eschatological promise is usually associated with the possibility of achievement of some kind of unity with the Ultimate Reality. Now, it is hard to see what second-order religion might have to offer by way of offsetting the disappointment most people experience at the gulf between 'what is' and 'what ought to be' or 'what might be', given Thornhill-Miller's and Millican's radically apophatic, almost agnostic, portrayal of the "luminous, secondorder ultimate reality of some kind that yet lies beyond the comprehension of all our individual efforts to point to it" (p. 49). Surely, learning that the universe is purposely finely tuned to make the existence of higher life forms possible does not - on its own - sound like sufficiently good news for the inhabitants of the planet, the majority of whom had no chance to reach maturity, and of those who had, only few had a chance to lead a life to which the term eudaimonia conceived in an Aristotelian fashion could be applied with any degree of plausibility, in which case they might perhaps have good reason to perceive their life as meaningful enough and not to hope for more.

All in all, a second-order religious belief based solely on the Fine-Tuning Argument - which might justify its claim to objective, scientific rationality can hardly be a religious belief, rather than a purely metaphysical or cosmological belief that does not involve religious attitudes of worship and orientation of one's existence towards God or the Ultimate Reality as its ultimate telos. Such second-order religion cannot provide an appropriate context for "intimations of divinity" (unless we conceive 'religious instinct' or 'religious sensitivity' in an expansive way unwarranted by the Fine-Tuning Argument). For this reason, it also cannot serve as a source of existentially relevant "sense of meaning", neither can it deliver any other "practical benefits", such as "comfort in times of grief".

\section{THE EXISTENTIAL IRRELEVANCE OF SECOND-ORDER RELIGION}

At this stage one might pause and ask oneself: how Branden Thornhill-Miller and Peter Millican might have arrived at such an extraordinary conception of second-order religious belief? My first reaction to their hypothesis was that of an awe how close it is to Hume's spirit. I thought that Hume would approve of all the conclusions of the paper, including the rejection of his own maxim on miracles. But then I have changed my mind and concluded that since Hume has admitted that he does not expect the majority of people to abandon their religious beliefs and practices, and since he accepted that 'human nature' itself leaves us no choice but to rely on instinct and imagination as providing context for or complementing the exercise of pure reason, would he choose to join Thornhill-Miller and Millican in their effort 
to articulate a sensible epistemology of religious belief, he would most likely give up any hope that religious belief may ever be justified in a rational way, and would not try to base it on the Fine-Tuning Argument or any other argument or empirical evidence. Instead, recognising that the secularisation thesis might be false, Hume would probably presuppose the existence of something like 'religious instinct', and then would simply allow religious believers to follow their religious instinct without expecting them to be able to rationally justify their particular religious beliefs (perhaps adding, as he should, that a religious believer, like every other reasonable person, is under rational obligation of ensuring coherence of his religious beliefs with his other well-established beliefs about the world). In other words, if Hume would have to grant that religious belief is in some sense natural, he would conceive of the epistemology of religious belief along fideistic lines, perhaps accepting Plantinga's externalist epistemology of religious belief, which under the condition of religious diversity may be considered to be a form of epistemologically sophisticated fideism. Allowing for that, Hume would probably see no reason why religious believers would have to stick to rigorously apophatic or agnostic approach to the Ultimate Reality, if religious instincts lead them to attribute to it certain particular characteristics, or to believe in a particular vision of relation between the Ultimate Reality to the world and humanity. After all, Hume will not expect any of these beliefs be justified in any other way than by reference to the religious instinct. Hume might also be aware that 'religious instinct' and 'religious imagination' play a pragmatic role in the religious sphere, analogical to that played by instinct and imagination in our interaction with the world and other people, so that relying on them and thus being religious is likely to involve not just 'believing in something' (holding certain beliefs), but 'doing something', 'adopting certain attitude towards God' ('believing God' vs. 'believing in God'), also 'undergoing something' (undergoing spiritual/metanoetic transformation), and 'hoping for something.' And to be able to do all that, believers have to hold some particular religious beliefs, perhaps many of them.

Thus, at the end Thornhill-Miller's and Millican's idea of second-order religious belief may not appear to be as Humean as one might expect it to be. If anything, it reminds one of Aristotle's vision of the Unmoved Mover putting the universe in motion. Aristotle may be able to say about his Absolute (as a 'thought thinking itself') more than Thornhill-Miller and Millican about their Designer of the finely-tuned universe, but this is so because part of what he says about the Unmoved Mover is based on a perfect being philosophy type of reasoning, not on abductive reasoning or inference to the best explanation which starts with the facts about the 
physical universe and postulates the existence of the Unmoved Mover. Aristotle's vision of the Absolute is a product of his agatological imagination. He thinks that an Absolute is a thought thinking itself, not interested in the universe, because his agatological imagination tells him that this is the optimal mode of existence.

Thornhill-Miller's and Millican's view of the "luminous second-order ultimate reality" shares some of the rational purity of Aristotle's vision, which does not require 'faith', but allows for full 'objectification' of our knowledge of the Absolute. Since the Aristotelian Absolute is not 'interested' in the world, possible insights in 'his' subjectivity or "intimations" of such an Absolute would be existentially irrelevant. An Aristotelian-style Absolute or a Designer of the finely-tuned universe cannot do more than explain the general teleology of the universe. It cannot be turned into existentially relevant God, because one important thing that Aristotle has shown by postulating the existence of the Unmoved Mover is that a 'non-religious' Absolute, lacking moral or agathological attributes, may fulfil the role of the explanans of the alleged teleology of the universe.

However, an existentially irrelevant Absolute is unlikely to be of interest for religious believers, because they are not primarily interested in finding the answer to the question: 'how did it all come about', but to the question: 'where is it all heading', and how the telos of the universe is related to the telos of their own individual existence. It is clearly a mistake to think that religion serves the purely epistemic needs of the people, satisfying their curiosity about the way the world came into being or who is responsible for the way the world operates. Arguably, even in the distant past when people ascribed to supernatural agency responsibility for the order of the seasons, the rising and setting of the Sun, for the rain and the drought, they were not interested in these phenomena in the existentially detached way a modern scientist might be, but they were interested in them as life-giving forces, whose very existence made them believe that someone cares about them or disapproves of their actions, and therefore their own existence may have some deeper meaning and some telos, other than survival for one more day. Only in this way one can explain why the growing awareness of the ability of science to account for the facts which in the past might have been 'explained' by reference to supernatural agency does not diminish in a dramatic way the tendency of people to believe in a theistic God or the Ultimate Reality conceived in some other way.

Ostensibly a 'religious mind' is not primarily interested in the explanation of natural phenomena by the reference to efficient causes, but is interested in an existentially relevant understanding - by reference to final causes - of 
the teleological nature of our axiological consciousness: our perceiving of the world in a non-detached way, as a value-laden world-for-us, as valuable when, and only when, viewed from particular subjective viewpoint of selfconscious subjects. To put it in a more Shakespearean manner, a religious mind perceives the world as a stage on which the drama of one's existence takes place. But the meaning of one's existence cannot be extracted from explanations of the origin or the workings of the 'stage' in terms of efficient causality, unless they also happen to entail answers regarding the telos and thus ultimate meaning of the 'play' of human existence, as is the case in the religious stories of creation. But science can say nothing definite about the telos and thus ultimate meaning of my existence, because this can be defined only by reference to some values, some 'good' towards which my existence is directed, and natural science cannot 'explain' values, because final causes do not belong to its domain. Thus a religious mind is neutral as to the explanation of the facts about the physical universe ('the stage'), hence Thornhill-Miller and Millican can stay reassured about the ability of adherents of first-order religions to "remaining fully committed to the enterprise of natural science" (p. 46). But a religious mind cannot remain fully detached from its existential concerns, limiting itself to Aristotelian contemplation of the "luminous, second-order ultimate reality of some kind that yet lies beyond the comprehension of all our individual efforts to point to it" (p. 49). Therefore, unless we want to engage in an implausible argument which starts with an admission that religion may after all be 'natural', because it does not seem to go away, and end with a recommendation that it should be replaced with a second-order religion which lacks nearly all the relevant characteristics of first-order religions to which billions of people adhere to, we have to accept that religious belief has to, above all, shed light on the question of the ultimate meaning of human existence, and this by reference to human values, not merely facts about the physical universe. For this reason, religious belief cannot lack soteriological/eschatological, metanoetic/ transformational, relational/inter-subjective, and other existentially relevant aspects, or else it is unlikely to appeal to adherents of first-order religions.

We have already raised the issue of the inability of second-order religion based solely on the Fine-Tuning Argument to be a source of meaning when it comes to human soteriological and eschatological concerns about our finiteness and mortality. Another specifically religious concern - one that bothered Kant - has to do with our awareness of our moral weakness and our limited moral perfectibility, combined with apparently 'natural' teleological inclination to be compelled by an ideal and to seek the ultimate good, while acting on this inclination is in most cases doomed to failure. Therefore 
providing a context for spiritual growth or metanoetic transformation 'transformation from self-centredness to other-centredness', to use John Hick's cross-cultural formulation - is perhaps the one aspect of religious belief that is universal across all religious traditions. Nota bene, this transformational aspect is in most cases closely related to the soteriological/ eschatological one, since metanoia, conversion or achieving freedom from 'craving' or attachment, is usually considered to be the condition of salvation/ liberation. In both cases, religious traditions provide some vision of the ultimate goal or at least a 'path' and direction in which one needs to proceed to actualise one's potential for inner transformation. For this reason spiritual paradigms or role models serving as guides on the path of transformation also typically constitute an essential part of religious traditions. While in some religious traditions (e.g., in certain Protestant denominations), belief itself may be all-important (although the affirmation of belief may at the same time be treated as a kind of 'conversion'), in most traditions, paradigmatically in most strands of Buddhism, all aspects of religion play an auxiliary role in the spiritual transformation.

This brings us to the famous Buddhist metaphor of a finger pointing at the moon, taken from Surangama Sutra, influential especially in the Chinese Chan Buddhism, which Thornhill-Miller and Millican utilise to conceptualise their view of the relationship between religious beliefs constituting particular religious traditions and the 'second order Ultimate Reality'. Their discussion of their Maxim of the Moon - poetic and rhetorically forceful - fills the final pages of the essay, and brings their argument to a close, summing up well both the critical and constructive components of their project. Everything we have said so far about secondorder religion finds its confirmation in Thornhill-Miller's and Millican's interpretation of this metaphor.

They start with rightly pointing out that the metaphor "cautions us against the blinding force of human cognitive bias by suggesting that all our pursuits of knowledge - including all our religions - are like 'fingers pointing at the moon', while all too often "we mistake our own finger for the moon and allow it to eclipse our view" (p. 49). However, what follows is a reading that expresses better Thornhill-Miller's and Millican's than Buddhist understanding as to what this metaphor is meant to imply as an instruction for an adept of Buddhism. Our authors interpret the metaphor as above all recommending radical apophaticism or agnosticism with regard to what can be understood and communicated about the ultimate reality by means of human religious concepts which give rise to diverse religious traditions. Making a link between the metaphor and their own project of 
removing irrational elements from religious belief systems, they write: "once we have rationally removed all the overlapping fingers associated with our different religions, there may be no distinguishing traits left to view" (p. 49). And yet, for some reason - perhaps once more becoming aware that their second-order religious belief might turn out to be empty of content and thus an improbable candidate for replacement to first-order religious beliefs - Thornhill-Miller and Millican attempt to qualify this apophaticism, suggesting that first-order religions "may also be thought to offer a reflection of second-order mysteries and wonders that yet still lie beyond our grasp" (p. 49). Whatever the meaning intended in this intricate phrase, given what has been said in the above two quotations, it is hard to see how ThornhillMiller and Millican can explain the way in which first-order religions might be a reflection of the Ultimate Reality.

Still, their hesitation regarding the extent of their apophaticism or agnosticism regarding the Ultimate Reality was well founded, because an all-out agnosticism implied in their own formulas would be out of place even in the context of Buddhism. Ascribing apophatic tendencies to Buddhism is, of course, uncontroversial, given that according to canonical sources Buddha consequently refused to comment about the nature of the Ultimate Reality (even though his Mahayana followers ended up developing a sophisticated trikaya metaphysics). What is controversial in ThornhillMiller's and Millican's reading of this metaphor is not so much what is in the text, but what is missing from it. What is the main point of the metaphor? What lesson is a Buddhist expected to draw from it? The conclusion presupposed in Thornhill-Miller's and Millican's 'Maxim of the Moon', that he should refrain from holding any particular religious beliefs specific to any particular religious tradition? Really? And only that? Surely not. After all, the metaphor is employed by Buddhists who always do belong to particular religious traditions and hold variety of religious beliefs which guide them in their spiritual practice aimed at metanoetic transformation and liberation. The main message of this metaphor is not negative (proscribing particular religious beliefs), but positive (prescribing spiritual practice, rather than just thinking and talking about the Ultimate Reality). The message of the metaphor is thus: do not just read, think and talk about the Buddha and Buddha-nature, because that will be like focusing your attention on the finger pointing to the moon. Instead, follow the path of spiritual discipline which will lead you to actually becoming Buddha, 'realising' the Ultimate Reality, which will be an equivalent of actually seeing the moon, rather than a finger. But such message presupposes quite particular religious beliefs: that the moon is actually there, and that it can be seen at the culminating 
point of a spiritual journey of metanoetic transformation, undertaken by an adept within the context of particular tradition defined by particular belief systems, sets of practices, institutions, etc., etc..

Thus, at the end, what is missing in Thornhill-Miller's and Millican's interpretation of the Buddhist metaphor of the finger pointing at the moon is precisely the same thing that is missing from their second-order religion, and which is there in Buddhism and other first-order religious traditions, namely soteriological/eschatological aspect (e.g., belief in the possibility of achieving Nirvana), metanoetic/transformational aspect (affirmation of centrality of certain spiritual practices aimed at liberation), and relational/ inter-subjective aspects (this will depend on the conception of the Ultimate Reality, but even in Buddhism which does not presuppose an existence of a Deity, practitioners adopt certain enduring relational attitude annunciated in the Buddhist initiation: "I take refuge in Buddha; I take refuge in Dharma; I take refuge in Sangha").

All these fundamental aspects of religious belief will have particular doxastic expressions, but the message of the metaphor of the finger and the moon remains universally valid: religious beliefs are only sign-posts on a spiritual path leading towards the union with the Ultimate Reality towards which the sign-posts only point, hence holding religious beliefs is just a point of departure of a spiritual journey, and does not exhaust the meaning of being religious. For this reason, attempting to establish the epistemic rationality of religious belief on a model of objective, scientific rationality, even for the price of emptying religious belief of its specifically religious content, would be like reading the metaphor of the finger and the moon in the following way. Since diverse religious beliefs are just different fingers pointing at the moon, typically eclipsing it, rather than disclosing it, a rational religious belief should consist in refraining from these particular first-order beliefs, and accepting that "there may be another vision of the moon, as a luminous, second-order ultimate reality of some kind that yet lies beyond the comprehension of all our individual efforts to point to it". And the only reason for adopting such a novel apophatic or agnostic attitude is that the postulated Designer of our allegedly finely-tuned universe may turn out to be a good candidate for the Ultimate Reality ('the moon'), although we will probably never know it, because there is no reason to think that there is a way to get to actually 'see' the moon, given that all alleged evidence of 'perceived supernatural agency' and all theistic arguments are inconclusive, while the Fine-Tuning Argument does not provide a basis for belief in an Ultimate Reality religiously conceived. And besides, why accept that there is a moon to be seen in the first place? After all, once we have 
accepted that the fingers of first-order religious traditions do not show the moon, but rather eclipse it, why to think that there is a moon? Perhaps the fingers do not refer to anything outside themselves, other than to the human needs which - in some Freudian fashion - gave rise to them (i.e., religious beliefs and traditions) as their efficient causes? Thus at the end, even the claim that the 'fingers' of first-order religious traditions 'eclipse' the Ultimate Reality turns out to be hard to defend.

To sum up, it seems that the only element of a rational second-order belief based on the Fine-Tuning Argument that is beyond criticism is the 'bare' Designer of the finely-tuned universe that looks more like Aristotle's Unmoved Mover after an apophatic diet, than a theistic God or the Ultimate Reality of oriental religions that religious believers have in mind affirming their religious commitment. Therefore, in order to have some positive content, a Universalist religious belief of the type Thornhill-Miller and Millican seem to have in mind, needs to be grounded in something more than the Fine-Tuning Argument, and this 'something' may be our axiological consciousness.

\section{RATIONALITY OF FIRST-ORDER RELIGIOUS BELIEF AND AGATHEISTIC PLURALISM}

Branden Thornhill-Miller's and Peter Millican's hypothesis of secondorder religious belief is motivated by twin concerns about alleged irrationality of first-order religious beliefs, and about their purported divisive and conflictual nature. Hence, in the remaining part of the paper, I will indicate briefly how an agatheist may go about addressing their concerns, while at the same time creating favourable conditions for constructive global ethical dialogue of adherents of various worldviews and religions. Much of what I have to say has already been implied in my critical remarks about Thornhill-Miller's and Millican's project.

\subsection{The nature and diversity of first-order agatheistic religious belief}

My reply to Thornhill-Miller's and Millican's concern about irrationality of a commitment to a first-order religious tradition boils down to a suggestion that to the extent agatheistic religious belief is presupposed in it as its doxastic core, its belief system, if internally coherent, may be shown to be rational, despite there being a plurality of such belief systems.

Returning to our picture of a doxastic ladder, with descending justificatory dependence, the nature of agatheistic religious belief may be argued to be such that it is reasonable to assume that more than one 'ladder' of a rational 
religious belief system may be 'hanged' at the 'ceiling' of the fundamental agatheistic belief. In other words, the fundamental agatheistic belief may constitute the epistemic foundation of a number of different religious belief systems.

In order to make sense of such a picture of the epistemology of religious belief, one has to begin by considering the following proposition. Of its nature, a religious belief system specific to a given religious tradition cannot be a product of some 'complete revelation' as if the 'ladder' of its complete doxastic system has been lowered down from heaven without creative contribution on the part of its adherents, neither can it be the sole product of abductive reasoning, starting from the facts about the physical universe and ending up with a complete system of beliefs about the Ultimate Reality, for the same reasons, discussed earlier, for which the Fine-Tuning Argument cannot provide a sufficient basis for a full-fledged religious belief system. Therefore, I submit, there is no better way to conceive of various religious belief systems than as products of the 'meeting of minds': human and Divine. Given the disparity between Divine mind and human mind stipulated in the religious conceptions of the Absolute, and the linguistic nature and historicity of human reason, even if the possibility of the Absolute self-disclosing itself to rational creatures in Nature, Scripture, History and religious experience is taken for granted, in order to make sense of the generation of the entire religious belief systems we need to presuppose that it is the human subjects, through their employment of agathological imagination as a rational faculty proper to all human beings, guided by the logic of perfect being philosophy, who form their beliefs about the Absolute in accordance with their sense of what is fitting to believe about the Absolute. The employment of agathological imagination in the formation of religious beliefs is indispensible, because religious beliefs are neither taken by the belief-holders to be beliefs about physical objects, nor are they beliefs about abstracts objects, nor beliefs about purely intentional objects like a work of art, but instead belong to a domain that is sui generis, and is such that in its exploration imagination must precede rational analysis. It is due to the involvement of imagination in the religious belief formation that religious language is ultimately irreducibly metaphorical, analogical and symbolic, and thus unavoidably anthropomorphic and always in need of purification by a combination of eminence and remotion (Aquinas's via eminentiae and via remotionis), that is by acknowledgement that the terms we use pertain to God always in a higher manner than we can actually conceive of, and by the removal of creaturely imperfections from our descriptions of the Absolute. Needless to say, this distinctive nature of religious belief, and the 
corresponding distinctive character of religious language, combined with the unavoidably perspectival, sociohistorical situatedness of believers as associated with particular times, places, cultures and languages, are bound to generate a diversity of religious concepts and beliefs.

Whatever the context in which particular religious beliefs are formed in various times and places - be it individual religious experiences or the activity of great religious figures as geniuses of agathological imagination there is no other way such beliefs might be widely accepted than by being 'recognised' as representing the optimal way of conceiving the nature of the Absolute and its relation to the world and humanity, where the 'optimal way' indicates an attempt at 'reading God's mind' or approximating 'God's eye view' of the matter. But the ability to 'recognise' a particular proposition about God or the Ultimate Reality as 'true' and thus worthy of assent, or a particular interpretation of a fragment of the sacred scriptures as 'correct' and thus worthy of belief, or for that matter, the ability to 'recognise' the Divine presence in one's own religious experience or in the activity of a great religious figure, presupposes having an a priori concept of God or the Ultimate Reality as the ultimate good. Without being, prior to experience, in possession of such a concept, we would not be able to make an agathological judgment, whether what we are dealing with is 'good enough' to be associated with God, otherwise we would have no basis for differentiation between God and something towards which an attitude that accords God would be inappropriate. It is, thus, my contention that all particular beliefs about the relation of God or the Ultimate Reality to the world, humanity, and to the belief-holder, are being formed and shaped by agathological imagination, and are being done so continuously, since our concept of the Ultimate Reality is necessarily an open, 'limetic', and hence also 'contested' concept, which can never be 'exhausted' by the human mind. This 'inexhaustibility' of the concept of God - corresponding to the inexhaustibility of the reality of God, well captured by the term 'Divine plenitude' - is yet another factor that explains the diversity of religious beliefs, as well as the evolving nature of religious beliefs in the course of history. In other words, the very nature of the Ultimate Reality as the 'object' of religious belief, coupled with the nature of human subjects of religious belief - as endowed with limited, linguistic, historical reason - makes us expect what we actually see: the diversity and evolving nature of religious belief systems. The importance of the sociohistorical situatedness of human subjects who shape their religious beliefs by exercising their agathological imagination cannot be overemphasised in this context, because religious beliefs are rarely beliefs of the kind Aristotle formed about his Absolute, as 
a 'thought thinking itself'. Instead, religious beliefs are typically beliefs about 'God-for-us', beliefs situating God vis-à-vis the believers in their particular context. Hence, the form most religious beliefs are likely to take will reflect the particular existential conditions of those who formed them, in a way that does not stand in contradiction with each believer's conviction that his belief is an optimal expression of truth about God available to him, because a believer has no other option, but to rely on his present agathological intuitions regarding the nature of God and God's relation to the world and humanity.

Nowhere is the impact of ever-changing existential conditions of beliefholders on the content of religious beliefs better documented than in the sacred scriptures of various religious traditions, which bear witness to the evolving nature of religious belief systems. For example, a parochial view of God as a tribal Israelite Divinity, to be found in some sections of the Pentateuch, from whom action in the spirit of favouritism is to be expected, even if that would entail allegedly approving a slaughter of the inhabitants of the entire Canaanite towns (cf. Deuteronomy 7.1-2; 20.16-18), could not be more different than the already universalist monotheistic vision of DeuteroIsaiah, who proclaims that the entire world is the dominion of Yahweh, drawing this conclusion from the belief that God is the sole creator of the universe ("It is I who made the earth and created mankind on it" - Isaiah 45:12). If one wishes to take these two visions of God as instances of the self-revelation of God to the people of Israel, surely one has to acknowledge that it would be hard to conceive of the possibility of God 'revealing himself' to the Israelites as a God of the entire universe at a much earlier stage of their history, before they had an opportunity to come, as exiles, into an intense contact with the cosmopolitan world of the Neo-Babylonian Empire, and with the universalist mindset of Cyrus the Great, both of which may be said to shape the agathological imagination of Deutero-Isaiah in a way analogical to that which made the universalist turn of the Jewish followers of Jesus of Nazareth, like the apostles Paul and Peter, possible.

A similar conceptual evolution is even more evident in the Vedas, the oldest of which apparently presuppose a polytheistic view of the religion of nature, hence the contrast with the vision of the Ultimate Reality found in the later Upanishads, informed by the mystical traditions of the Indian sub-continent, could not be more dramatic.

Needless to say, in such cases the sacred scriptures may be interpreted in a coherent way by reading the earlier texts through the lenses of the later developed views of the Absolute, which at the moment of the reading of the scriptures are taken by the adherents of the given tradition to approximate in 
an optimal way the ultimate truth about the Absolute. If we add to this picture the revolutionary aspects of the Buddha's religious and social teaching, that includes challenging social inequalities sanctioned by the Vedic tradition something that the Prophet Muhammad also did in the Arab context - it is hard not to be struck by the progressive nature of the evolution of religious belief systems. Again, such evolution can be best accounted for by reference to the agathological imagination of religious geniuses, whom their encounter with the Absolute leads to re-imagining not just the relation between the Ultimate Reality and our human world, but also the human reality as seen from 'God's eye viewpoint', in its tension between 'what is' and 'what ought to be' or 'what might be'. This process of agathological reimagining, leading to the revision of certain beliefs and practices of a given tradition, is thus motivated by the attempt at approximating more fully to 'God's eye view' the human way of perceiving the potentialities for good inherent in the human reality, and to the extent this process can be thought to lead adherents of a particular religious tradition to grasping more fully the meaning of the good that is realised completely in God or the Ultimate Reality, adhering to such religious tradition is consistent with adhering to the fundamental agatheistic belief, despite there being a plurality of such evolving religious traditions.

It is important to notice that it is not just by revising the canonical elements of the religious belief systems adhered to at an earlier stage - in response to new agathological insights that make certain religious beliefs and practices appear outdated to the belief-holders - that religious traditions are formed and re-formed. At least equally significant is the employment of agathological imagination in interpreting the canonical beliefs, texts, narratives and symbols in various times and places, without revising them in a dramatic fashion that might undermine the confidence of the believers in the integrity of their religious tradition and its identity over time. Here the scope for diversity is again considerable, although such diversity may be easily overlooked, precisely because this time one does not deal with fundamental change of the canonical elements of a religious belief system - exemplified by Buddhism emerging from Hinduism or Christianity emerging from Judaism - but instead with internal diversity within one religious tradition, as is the case with differences between various Buddhist, Hindu, Muslim, Jewish and Christian 'denominations', interpreting differently the canonical beliefs, and moreover is the case with differences between individual adherents of the same denomination, because the agathological imagination, like Aristotle's phronesis, is ultimately an individual faculty, although its deliverances can be inter-subjectively communicated and debated. 
This kind of 'horizontal' doxastic diversity within religious traditions, which appears to be less dramatic, but is no less important from the epistemological point of view, than the diversity of religious traditions, is complemented by a 'vertical' interpretative diversity resulting from evolution of interpretation of the canonical beliefs over time. One notable example of vertical doxastic diversity would be that of the interpretation of the canonical biblical belief about God being just vis-a-vis his human creatures. Such belief is supposed to shed light on the appropriate form of human relations as just or unjust, as seen from a 'God's eye viewpoint'. And yet, even without providing extensive arguments of a historical nature mentioning the history of slavery and of the resistance to democracy should suffice - it is not difficult to establish the claim that religions, including the Abrahamic religions, have an (un)impressive record of opposition to recognition of equal worth of every human person, and to social changes associated with the promotion of greater social equality. However, it is clear that each time humanity's horizon of agathological imagination has been expanding, leading to a recognition - to a greater degree - of the fundamental equality of human beings, the interpretations of the canonical religious texts and beliefs kept changing, as an expression of acknowledgement that the goodness and justice of God has at an earlier point in time been less adequately conceived.

These changes in the understanding of the agathological attributes ascribed to the Absolute in various religious traditions take place within a hermeneutic circle, where new insights into the nature of human goodness affect the way we conceive of Divine goodness, and vice versa. In a sense, as the believers grow, expanding the horizon of their agathological imagination, so does their God, and in turn the 'growing' God challenges the agathological intuitions of those of his believers who did not yet 'update' their agathological beliefs in line with the new insights of the agathological geniuses - saints, prophets and sages - of their tradition. Such dialectical progress can be made sense of by reference to the intuition that is present in one way or the other in the majority of religious traditions, and in the Judeo-Christian context is expressed in the belief that human beings are created by God in the 'image' and 'likeness' of God (cf. Genesis 1:26-27; $5: 1-3 ; 9: 6)$. The imago Dei axiom allows one to argue that even though God's absolute nature - which calls for the application of the analogy of proportionality in making any assertions about God on the basis of the qualities shared by human beings with God - seriously limits our ability to 'see God's face' in the mirror of our humanity, still at least as much of the trace of the Divine in humanity is discernible, namely human openness to 
the realisation of the original potential for imitating God in his goodness (which is also consistent with the agatheistic identification of God with the ultimate good). This line of thought reinforces the conclusion that religious believers are always caught in a hermeneutical circle and cannot transcend their human condition to actually achieve a 'view from nowhere' or the 'God's eye view', and base their religious belief system solely on a 'theology from above' strictly understood, if this term would be taken to refer to a set of propositions about the way God relates to his creatures that would have an ahistorically fixed meaning and so would be unable to be affected by the evolution of our agathological intuitions.

By now, one thing should be clear: to paraphrase Rousseau, taking God as God might be, and humans as they are, one should expect to see what we actually see: pluralism of evolving religious belief systems. To the extent God as Agatheos - the Ultimate Reality religiously conceived and identified with the Ultimate Good - is thought to infinitely transcend the limited cognitive and imaginative capacities of the human mind that is embodied and thus sociohistorically situated, the pluralism of religious beliefs is a natural outcome of human efforts to articulate human understanding of God, and this holds whether one chooses to see the history of religion in terms of ' $m a n$ in search of God' or 'God in search of man'.

Thus, although so far we have discussed only the intensional rather than extensional side of the problem of religious belief, that is its possible meanings, rather than the existence of its referent, the reason why the above discussion of the nature of agatheistic religious belief was necessary is that if first-order religious belief is to be epistemically justifiable in a non-fideistic way, it is unavoidably going to be this kind of belief that is part of one among many evolving religious belief systems justified in a similar way.

\subsection{The nature and epistemic justification of first-order agatheistic religious belief}

From what has been said so far about what can and what can not constitute the possible epistemic ground of the first-order religious belief system, it follows that it is a mistake to assume that each particular religious belief that constitutes a part of a religious belief system should be justified separately by reference to some 'conclusive evidence' of empirical nature. Instead, I submit that the epistemic justification of religious belief should be conceived along the lines of the metaphor of a doxastic ladder hanging at the ceiling of the fundamental agatheistic belief in the Ultimate Reality as the ultimate good. All particular beliefs of a given religious belief system are justified against the background of their antecedent probability relative 
to what the fundamental agatheistic belief may be thought to entail, that is they are justified to the extent they are part of an internally coherent belief system which coheres with the fundamental agatheistic belief. In practice, particular religious beliefs are added to the system by great religious figures as geniuses of agathological imagination who have new insights regarding what God or the Ultimate Reality being the ultimate good might imply, and who also typically are taken to have some kind of religious experience understood as an instance of an 'encounter' with the Divine. But these new beliefs have its primary justificatory ground not in the experiences themselves, since such ground would be insufficient for justification, but in the fundamental agatheistic belief. Therefore, what an epistemologist of religious belief has to concentrate on in the first place is the possibility of epistemic justification of the fundamental agatheistic belief itself, which in turn grounds all other first-order religious beliefs that may also be epistemically supported by religious experience to the extent religious experience is itself made antecedently probable by the fundamental agatheistic belief, and is consistent with it.

Accordingly, the main claim of this section of the paper is that agatheistic religious belief can be shown to be rational by recourse to a combination of two lines of argument: the first one which postulates the existence of Agatheos as the ultimate good to which our axiological consciousness points, and the second one which is supplementary, and points to the experiential factors, namely the agathonic feeling accompanying agatheistic religious attitude and religious experiences of the Divine presence.

Thus, the main argument in favour of rationality of agatheistic religious belief starts with identifying the fundamental 'fact' about our axiological consciousness, our directedness towards the good, as "that for which everything is done", identified already by Plato (Gorgias 468b; cf. also Symposium 205e-6a, Republic 505d-e, Philebus 65a). Aristotle's concept of intrinsic good as desired for itself and occupying the supreme position in the hierarchy of human ends, something we would choose and pursue whether or not it helps to bring about further goods (cf. Nicomachean Ethics I.2 1094a19, I.6 1096b18-19, I.7 1097b2-5), although taking on a different meaning due to a different metaphysical context, confirms Plato's insight about the irreducibly value-laden nature of our attitude towards reality. While Aristotle's account of a flourishing life includes a vision of a purely contemplative existence, it is clear that far more realistic and existentially relevant is his vision of an active life, deeply engaged with the world, in which the desire to know is always inseparably linked with seeking some good, according to the axiom: to know a good, is to desire it. 
A crucial step in our argument is to reject the possibility of a satisfactory scientific explanation of this axiological dimension of our consciousness that would make it unproblematic, leaving no questions unanswered. And this is the right moment to draw the attention to the opening quotations from Albert Einstein and Isaiah Berlin. I deliberately chose two authors who did not consider themselves theists, yet - while being exemplary rationalists refused to identify themselves as critics of religion as such or as atheists, ${ }^{22}$ as did Hilary Putnam who voiced similar opinions on the subject while remaining a non-theist and characterising the God of his own Jewish religious practice as a "human construct" created "in response to demands that we do not create". ${ }^{23}$ Identifying oneself as a theist or not is beside the point in the above quotations which point to the normative aspect of the 'human world', of the world of conscious subjective experience, that is not reducible to the facts about the physical universe, and as such cannot be explained exhaustively by science, while presenting itself to us as a central human concern that is hard to dismiss without making sense of it or giving it some meaning that would be relevant to our first-person perspective on the world and our own being in the world. It seems that it is this characteristic tendency of human beings as 'sense-making' or 'meaning-giving' animals that makes our minds restless and does not allow us to give up the search for the ultimate meaning even in the areas where there is perhaps no scientific knowledge to be had, and therefore also no possibility of reliance on the scientific method, and no possibility of conflict with science, as Einstein, Berlin, and Hume - with his formula that one cannot derive 'ought' from 'is' - seem to agree, even though some contemporary naturalists may wish to believe that science can determine human values and human ends.

The reason why science cannot either confirm or disconfirm religious belief is that religious belief - even if 'acquired' in the context of a religious community and drawing on the resources of a religious tradition - is about the aspect of reality that is essentially subjective, expressing our particular, first-person, specifically human perspective on the world. Religious belief pertains primarily to the realm of values, the realm of the ultimate good, not to the realm of facts about the physical universe, whose phenomena are explained by science giving account of the causal laws that explain them. But the axiological dimension of the human consciousness presents itself to us

${ }^{22}$ Asked about it, Isaiah Berlin explained: "dry atheists seem to me blind and deaf to some forms of profound human experience." (Cf. Isaiah Berlin and Ramin Jahanbegloo, Conversations with Isaiah Berlin (New York: Charles Scribner's Sons, 1991), p. 110.)

${ }^{23}$ Hilary Putnam, Jewish Philosophy as a Guide to Life: Rosenzweig, Buber, Levinas, Wittgenstein (Bloomington: Indiana University Press, 2008), p. 6. 
as irreducibly teleological, not efficient-causal, therefore there is nothing for science to explain in the realm to which religious beliefs - and all agathological beliefs, whether held by a religious believer or by an atheist - pertain. For this reason, to attempt to take out religious belief from its subjective, firstperson context, in order to make it appear more rational than it actually is, is like taking a fish out of the water to make it easier to observe. From the fact that it may be possible to think of a religious belief that would have a stronger claim to rationality than the kind of religious belief that is actually held by a typical religious believer, it does not follow that we have a good reason to replace the former with the latter, as Thornhill-Miller and Millican propose. At the end it may turn out that these two different kinds of beliefs simply do not capture the same dimension of 'reality' in question, as the 'more rational' beliefs about the acoustic and mathematical aspects of the Art of the Fugue cannot replace the 'less rational' beliefs about the music formed in the mind of the listener of Bach's masterpiece. The objective and subjective point of view of the matter are not reducible to each other. Something of this duality seems to be present in Thornhill-Miller's and Millican's approach to religious belief, as if the chief reason why they choose to focus on fine-tuning is that they want to put the spotlight on that dimension of religious belief which is most easily objectifiable and thus conducive of rational justification according to the paradigm of objective scientific rationality, and this despite the fact that it turns out to be the least relevant aspect of religious belief from the believer's point of view, who, as it were, is interested in the 'music' (the subjective aspect), not in its physical medium (the objectifiable aspect) of the phenomenon under consideration. Religious belief is 'at home' in the domain of subjectivity (or better to say, inter-subjectivity), and both the professional critics and professional defenders of religion who for the sake of their theistic or atheistic 'apologetics' bring to the fore the aspects of religious belief that are most 'objectifiable', miss the point of what religion is really about, and fight their battles somewhere on the outskirts of the 'garden of faith' which seems to be flourishing as well as ever, taking on new colours as generations of believers pass.

However, by affirming that science cannot confirm or disconfirm religious belief, or that science is of no help when it comes to making sense of our axiological consciousness, I do not mean to imply that our directedness towards the good, which makes us endlessly seek some good, and leaves us always dissatisfied, looking forward towards the realisation of some higher good not yet realised, could not be made sense of without reference to the ultimate good religiously conceived. On the contrary, every question that leads some people in the direction of a religious answer can be answered in 
a non-religious way. Moreover, there is always an absurdist option available consisting in acceptance that the myth of Sisyphus expresses well the truth about the human condition, thus endorsing a 'tragic' vision that there simply exists an ill-fit between our way of perceiving the world - resulting perhaps from our evolutionary development - and what reality can actually offer. The absurdist answer recognises the fact of our axiological open-endedness, and our directedness towards the horizon of the ultimate good, while denying that there exists anything real and realisable that corresponds to our concept of the ultimate good. An absurdist - in a style of Camus - does not have to deny that many 'parts' of our human world, including morality, may be meaningful, but concludes that there is nothing contradictory in 'parts' being meaningful, while the 'whole' lacking ultimate meaning. Presumably, a typical non-religious and non-absurdist response to the issue of 'the ultimate good' is likely to take a form of some variation on the Aristotelian theme of 'human flourishing' that is in principle possible in the present human condition. But a religious mind finds all the non-religious options, including the Aristotelian one, unsatisfactory as ways of making sense of the riddle of our axiological consciousness, and conceptualises in religious terms the ultimate good as the telos of human life, most likely portraying the human condition in a way akin to Augustine's intuition expressed at the very beginning of his Confessions that portrays God as a kind of powerful 'magnet' of the ultimate good that draws the creatures to himself as the source and the end of all that is good: "for Thou hast formed us for Thyself, and our hearts are restless till they find rest in Thee." 24

But how to describe this choice between various available 'options' in epistemic terms? Given that variety of worldviews may be coherent with the undisputable findings of science, and given that each of them may be internally coherent, it seems there can be no other ultimate basis of this fateful choice between various comprehensive worldviews - differing primarily in the way they define the ultimate good and the ultimate meaning of human existence - than the agathological imagination that leads various people to choose various 'agathological landscapes' as agathologically optimal, or to put it differently, as conceptualising in the optimal way the potentialities for good inherent in the human reality. One might ask, how does such a choice differ from a fideistic 'leap of faith' into epistemic darkness in which there is no knowledge to be had? There are a number of differences. Firstly, the choice is of such a nature that it is unavoidable: every human being that leads a life that is to some degree an examined life, has a comprehensive

${ }^{24}$ St. Augustine, Confessions, trans. by Henry Chadwick (Oxford: Oxford University Press, 1998), p. 24. 
worldview which includes such elements as an understanding of the ultimate good and the ultimate meaning of one's existence, which cannot be settled in an objective scientific manner. Secondly, the choice is not really arbitrary, because it is a choice between various conceptions of the ultimate good, and it is in all probability a choice that is made in manner that could be best analysed in externalist terms, that is as only to a limited degree voluntary and conscious. Thirdly, the choice itself, and the life in accordance with that choice, is accompanied by this experiential element that we called the 'agathonic feeling' that serves as a kind of agathological conscience, which at the same time can be taken to be the only epistemic compass available in the realm of the good. 'Agathonic feeling' accompanies 'agathological choices' of every subject, whatever his worldview, but in the context of 'religious life', especially if it takes a form of intense spiritual practice leading to a progress on the path of metanoetic transformation, there will be many occasions to be aware of this 'inner testimony' manifesting itself in variety of subtle ways, indicating the position of the 'traveller' vis-à-vis the 'destination' of the 'journey', that is the Ultimate Reality identified with the ultimate good. Fourthly, and lastly, it is not the case that the agathological beliefs, whether leading to a religious or non-religious worldview, are immune to rational criticism, in the way the religious beliefs of a fideist might be, since it is presumed that in order to deserve to be called rational, religious beliefs have to constitute a part of a belief system that is internally coherent and coherent with the undisputed findings of science. ${ }^{25}$

There is one more fundamental reason which can be clearly discerned in the religious literature as a sort of 'explanation' of the inclination of religious mind to prefer a religious conceptualisation of the ultimate good, rather than a non-religious one, but this 'reason' is not independent of the exercise of agathological imagination, but only reveals its inner logic, that is the logic of perfect being philosophy. It is the intuitive inclination to perceive the present human condition and the present circumstances of human existence as sub-optimal, unsatisfactory and disappointing. This inclination and its opposite capture well the fundamental difference between Plato's and

${ }^{25}$ It seems that the dynamics of this choice between various visions of the ultimate good, and the corresponding choice between various comprehensive worldviews, is somewhat akin to what Wittgenstein might have in mind when applying his idea of 'form of life' and the corresponding 'language game' to the case of religious belief. He also thought that the choice is being made between the entire 'doxastic ladders' or conceptual frameworks, rather than by considering the rationality of particular religious beliefs (e.g., belief in the Last Judgment). (Cf. Ludwig Wittgenstein, Lectures and Conversations on Aesthetics, Psychology, Religious Belief, ed. by Cyril Barrett (Oxford: Blackwell, 1966), pp. 53ff.) 
Aristotle's visions of reality and their visions of a good life, which arguably influenced most of the metaphysical and axiological alternatives articulated by Western philosophy. Again, this difference can be accounted for by the differences in the way Plato's and Aristotle's agathological imagination has functioned, and there is little one could do by way of rational argument to settle the matter which of those two approaches is more 'rational'. This much is clear, a religious mind perceives as rationally unacceptable the discrepancy between teleology of our axiological consciousness presenting itself to us as categorical and therefore difficult to explain away by reference to social factors - and the practical impossibility of realisation of the good to which our axiological consciousness points as the telos of our existence. The impression that teleology identified in our mental life makes on a religious believer is being reinforced by the impression of teleology discerned in the workings of the universe ('the starry sky above me and the moral law within me'), so that when a naturalist suggests that the workings of the universe can at the end be explained entirely in efficient-causal way, a religious believer faces a choice between a causally closed view of reality accounted for by references to efficient causes and an essentially teleological view of reality. But being aware that science can never conclusively confirm the veridicality of the former view, a religious believer opts for the latter, since his agathological imagination leads him to embrace the latter option as agathologically preferable.

At the end, the choices between various conceptions of the ultimate good take a form of a postulate of practical reason which is an object of rational belief, but the reasons for the belief are of practical nature, that is pertaining to our acts of will and our actions. As such, they cannot be settled by science, because they pertain to the question about 'what ought to be' or 'what might be', not 'what is'. More generally, nothing more can be done to establish the rationality of agathological beliefs, whether held by theists or atheists, than - following Plato, Aristotle, Augustine, Aquinas and Kant - to point to the concept of the ultimate good as the transcendental condition of our axiological consciousness, and to see agathological beliefs as objects of Kantian 'rational faith' or, better, of rational hope. Thus, agatheism, while not being a form of fideism, is a form of 'sperantism' (from Latin sperare - to hope) - and so is every other comprehensive worldview, whether religious or naturalistic, because every worldview includes agathological beliefs that are objects of rational hope.

As to the evidential value of religious experience, conceived as an experience of the Divine presence, religious experience does play an important supporting role in establishing the rationality of agatheistic 
first-order religious belief, but it cannot be treated as an independent ground, because it is itself grounded in the agatheistic religious belief. Mystical literature testifies that mystics experiencing the presence of God or the Ultimate Reality, form at least three types of belief: (a) the reality that is experienced is supremely real, (b) the object of experience is exceedingly good, and (c) the object of experience appears to transcend entirely the mundane reality in which the subject is immersed. In order to be able to identify the 'object' of an experience as God or the Ultimate Reality, rather than as something else, the mystic has to possess an agatheistic concept of the Ultimate Reality prior to experience. In a different place I argued at length pace Alston - that plurality of mystical traditions does not contradict the possibility of authenticity or veridicality of such experiences occurring in the context of a variety of religious traditions. ${ }^{26} \mathrm{I}$ argued in favour of the coherence of a view I called 'mystical inclusivism' which (1) allows for the possibility of veridical experience of God or the Ultimate Reality in a variety of religious traditions, but (2) avoids the radical revisionist postulates of Hickian pluralism, akin to the revisionism advocated by Thornhill-Miller and Millican, and (3) it leaves open the question whether the creed of any specific tradition is a better approximation to the truth about the Ultimate Reality than the creeds of other traditions, thus creating a space for a kind of pan-inclusivism as a form of religious inclusivism which acknowledges that everyone else is also an inclusivist. Such pan-inclusivism is fully coherent with the epistemology of agatheistic religious belief presupposed in this paper that accommodates religious diversity without advocating abandoning first-order religious belief.

\section{CONCLUSION}

The possibility of a rational agatheistic religious belief solves ThornhillMiller's and Millican's Common-Core/Diversity Dilemma: "That in so far as religious phenomena (e.g. miracle reports, religious experiences, or other apparent perceptions of supernatural agency) point towards specific aspects of particular religions their diversity and mutual opposition undermines their evidential force; while in so far as such phenomena involve a 'common core' of similarity, they point towards a proximate common cause for these phenomena that is natural rather than supernatural." On the agatheistic picture, the above dilemma rests on a problematic view of the nature and epistemic grounds of religious belief which I have tried to

${ }^{26}$ Cf. Janusz Salamon, "Light Out Of Plenitude: Towards Epistemology of Mystical Inclusivism”, European Journal for Philosophy of Religion, 2 (2010), pp. 141-175. 
disclose. Firstly, the 'religious phenomena' to which our authors point to do not constitute the main epistemic ground of first-order religious belief. Indeed, they cannot constitute such ground without being dependent on the fundamental agatheistic religious belief that identifies the Ultimate Reality with the ultimate good and which itself is not grounded in any such 'religious phenomena'.

Secondly, to the extent such phenomena are at all called upon by religious believers in the capacity of 'evidence' for the existence of the 'object' of religious belief - and they rarely are - they do not and can not "point towards specific aspects of particular religions", if by this we mean establishing the truth of particular religious beliefs about the Absolute and its relation to the world, since no empirical data can confirm religious beliefs about the Absolute held by adherents of any religions. Any such empirical data, in order to be interpreted as evidence of anything related to the Absolute, presupposes the possession by the subject of an a priori concept of the Absolute which cannot itself be derived entirely from empirical data. In practice, such 'religious phenomena' play a different role than Thornhill-Miller and Millican ascribe to it, namely as a source of motivation, encouragement and reassurance on a path of spiritual development leading to metanoetic transformation, but this role presupposes a pre-existent religious belief, rather than grounding it. So conceived, religious experiences or other such 'religious phenomena' cannot be 'opposed' to each other, and nothing of epistemic significance follows from their diversity.

Thirdly, the presupposition of the 'common core' in diverse religious traditions offers no problem, if the fundamental agatheistic religious belief constitutes such a 'common core' as it arguably does in reality. 'Religious phenomena' of the kind Thornhill-Miller and Millican refer to do not and can not constitute a 'core' of any religious tradition, therefore similarities or dissimilarities between such 'religious phenomena' are of secondary relevance for the epistemology of religious belief. As to agatheistic religious belief as the 'common core' of diverse religious belief systems, such belief cannot be explained away by reference to any 'natural cause', proximate or otherwise. And as to the possibility of explaining away all religious experiences by reference to proximate causes, William Alston argued convincingly in his Perceiving God that an ability to identify a proximate cause of a religious experience does not exclude the possibility that this experience is a veridical perception of the Divine presence, since God may feature further back in the chain of causes. When I see a tree, there are proximate causes of my perceiving the tree other than the tree itself, and specifying how proximate a cause of a perception has to be - especially when 
the Divine presence is supposed to be the object of experience - to make the perception veridical cannot be settled by way of philosophical argument. In short, we have a 'common core' and diversity, but no dilemma.

By now the connection between agatheistic vision of religious belief and the global ethical dialogue should be clear. Agatheism sees religious belief systems as grounded in the exercise of agathological imagination that struggles to give an expression to our concern with human values and human good. Thus, agatheism locates religion not in the realm of extraordinary 'religious phenomena' that might be perceived as exotic and irrelevant by an atheist, but rather in the sphere of central human concerns which bother every human being. In this sphere all human beings are on par, because science cannot settle the most vital matters of the ultimate good and the ultimate meaning of human existence. It is also the sphere in which human beings - communicating and justifying to each other their agathological beliefs - have to find the ways to live a solidary life on a global scale, mindful of the global ethical imperative to act so as to promote the chances of all to realise in their life the potentialities for good inherent in human reality. 